\title{
Cladistic analysis of the family Stenothoidae (Amphipoda, Crustacea)
}

\author{
Traudl Krapp-Schickel ${ }^{1}$, Stefan Koenemann ${ }^{2}$ \\ ${ }^{1}$ Forschungsinstitut und Museum A. Koenig, Bonn; traudl.krapp@uni-bonn.de; ${ }^{2}$ Institut für Tierökologie und \\ Zellbiologie, Tierärztliche Hochschule Hannover; stefan.koenemann@tiho-hannover.de
}

Key words: Taxonomy, Amphipoda, Stenothoidae, Thaumatelsonidae, phylogenetic analysis

\begin{abstract}
The amphipod family Stenothoidae contains more than 200 species in about 40 genera; these genera are at present often defined not by the presence, but by the absence of synapomorphies, thus defining grades rather than clades. Our phylogenetic analyses yielded 4 groups of stenothoids: a basic proboloidid clade; an advanced and always clearly separated Austral-Antarctic thaumatelsonid clade, with a possibly related Arctic mesometopid clade; and finally a poorly resolved group, the stenothoids sensu stricto, including the large and probably polyphyletic genera Stenothoe and Metopa, each with more than 50 species. It is proposed to study and analyse these groups separately in future, based on better redescriptions of the individual species. Our analyses support the family status of the Thaumatelsonidae, erected as a family by Gurjanova in 1938, but reduced to subfamily rank by Barnard in 1972.
\end{abstract}

\section{Contents}

\begin{tabular}{|c|c|}
\hline Introduction & 169 \\
\hline Material and methods ........ & 172 \\
\hline Choice of taxa & 172 \\
\hline Cladistic analyses ................. & 172 \\
\hline Characters and their states & 173 \\
\hline 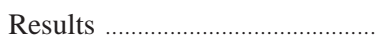 & 178 \\
\hline Discussion and conclusions ...... & 180 \\
\hline Clades within Stenothoidae & 180 \\
\hline 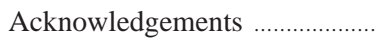 & 10 \\
\hline References ...................... & \\
\hline
\end{tabular}

\section{Introduction}

The amphipod families Stenothoidae and Amphilochidae were established by Boeck (1871) as subfamilies of the Leucothoidae; Sars (1892) elevated both to family rank. They have traditionally been considered close relatives, with the Amphilochidae the more plesiomorphic family, with character states such as a widened basis of the fifth peraeopod, a biramous third uropod, and not very specialized mouthparts. Bousfield (1982) placed both Amphilochidae and Stenothoidae in his superfamily Leucothoidea. Stenothoidae are defined by a very small and for the most part hidden coxa 1, a greatly enlarged, shield-like coxa 4, a linear basis of peraeopod 5 and a uniramous uropod 3; mouthparts are narrow and specialized. Some members show clear sexual dimorphism, while others do not.

Barnard and Karaman (1991: 684) divide 32 stenothoid genera into two large groups, using the shape of the basis of peraeopod 7: half of the genera have this basis rounded and expanded. They include the two large genera Stenothoe and Metopa, each with more than 50 species, as well as Metopoides, Proboloides and Torometopa, together also more than 50 species.

The remaining genera have a linear basis on peraeopods 6 and 7, with some transitional forms. A group of Antarctic genera shares the following apomorphies: a nasiform antennal process, an enlarged peraeonite 4 with trapezium-shaped (vs. triangular) coxa 4, and a three-dimensionally thickened, immovable (vs. horizontally flappable) telson. These genera were first separated from Stenothoidae as the family Thaumatelsonidae by Gurjanova (1938), but subsequently reincluded again as subfamily Thaumatelsoninae by Barnard (1972).

Furthermore, genera in Stenothoidae are traditionally separated by characters such as the number of articles in the accessory flagellum or the palp articles of moutparts. However, fusion or loss of articles may 
Fig.1. Matrix of

61 taxa and

43 characters.

Gammarus sp.

Cressa dubia

Gitanopsis inermis

Gitana sarsi

Stegoplax longirostris

Cyproidea ornata

Aurometopa aurorae

Hardametopa nasuta

Knysmetopa grandimana

Mesometopa neglecta

Mesoproboloides excavata

Mesostenothoides perrieri

Mesostenothoides pirloti

Metopa bruzelii

Metopa clypeata

Metopa leptocarpa

Metopella angusta

Metopella longimana

Metopelloides micropalpa

Metopoides magellanica

Microstenothoe ascidiae

Parametopa crassicornis

Parametopa kervillei

Parametopella cypris

Paraprobolisca leptopoda

Probolisca elliptica

Probolisca ovata

Proboloides gregaria

Proboloides typica

Prometopa tuberculata

Prostenothoe sextone

Scaphodactylus foliodactylus

Scaphodactylus gigantocheirus

Sthenometopa palmata

Stenothoe brevicornis

Stenothoe megacheir

Montaguana monoculoides

Stenothoe valida

Stenula carinata

Stenula rubrovittata

Torometopa crenatipalmata

Torometopa medipa

Torometopa perlata

Vonimetopa dubia

Wallametopa cabon

Zaikometopa erythrophthalm.

Antatelson walkeri

Ausatelson ule

Chucullba alla

Goratelson warroo

Parathaumatelson nasicum

Prothaumatelson nasutum

Pseudothaumatelson patagonic. 1

Pycnopyge carinatum

Ptychotelson virdurorum

Raumahara dertoo

Raukumara rongo

Thaumatelson herdmani

Thaumatelsonella kingelepha

Verticotelson mantis

Yarra unguiserra

0

0

0

0

0
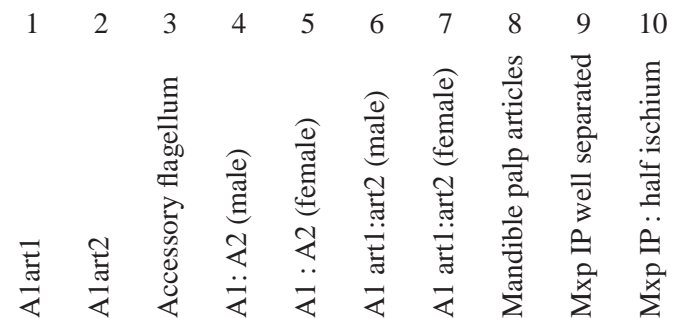

$11 \quad 12$

$\begin{array}{lllllll}2 & 13 & 14 & 15 & 16 & 17 & 18\end{array}$

19
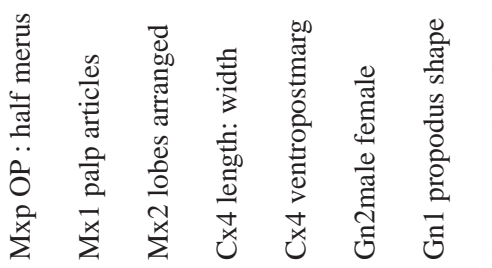

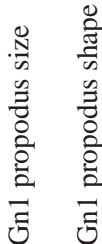

$\begin{array}{lllllllllllll}0 & 0 & 0 & 0 & 0 & 1 & 1 & 0 & 0 & 0 & 0 & 0 & 0 \\ 0 & 0 & 1 & 0 & 0 & 0 & 1 & 0 & 0 & 0 & 1 & 1 & 1 \\ 0 & 0 & 1 & 0 & 0 & 1 & 1 & 0 & 0 & 0 & 0 & 0 & 0 \\ 0 & 0 & 1 & 0 & 0 & 1 & 1 & 0 & 0 & 0 & 0 & 1 & 0\end{array}$

$\begin{array}{lllllll}1 & 0 & 1 & 0 & 0 & 0 & 0\end{array}$

$\begin{array}{lllll}0 & 1 & 1 & 0 & 0 \\ 0 & 0 & 1 & 1 & 2\end{array}$

$\begin{array}{lllllll}1 & 0 & 1 & \text { ? } & 1 & 0 & 0\end{array}$

$\begin{array}{lll}0 & 0 & 1\end{array}$

$\begin{array}{llll}0 & 1 & 1 & 1\end{array}$

$\begin{array}{lllllllllllllllllll}0 & 0 & 1 & 2 & ? & 0 & ? & 2 & 0 & 0 & 1 & 1 & 2 & 1 & 0 & 1 & 1 & 2 & 0 \\ 0 & 0 & 1 & 2 & 2 & 0 & 0 & 2 & 0 & 1 & 1 & 1 & 1 & ? & 0 & 1 & 1 & 2 & 1 \\ 0 & 0 & 1 & 0 & 1 & 0 & 0 & 0 & 0 & 1 & 2 & 1 & ? & 1 & 0 & 0 & 1 & 1 & 1\end{array}$

$\begin{array}{lllll}0 & 0 & 1 & \text { ? } & 2\end{array}$

$\begin{array}{lllllllllllllllllll}0 & 0 & 1 & 1 & 1 & 1 & 0 & 0 & 0 & ? & ? & 1 & 0 & 1 & 0 & 1 & 1 & 2\end{array}$

$\begin{array}{lllllllllllllllllll}0 & 0 & 1 & 1 & 1 & 0 & 0 & 2 & 1 & 0 & 0 & 1 & 1 & 1 & 0 & 1 & 1 & 2 & 0 \\ 0 & 0 & 0 & ? & 2 & ? & 0 & 0 & 0 & 1 & 1 & 0 & 1 & 1 & 0 & ? & 0 & 1 & 0\end{array}$

$\begin{array}{rlllllllllllllllllr}0 & 0 & 1 & 1 & 1 & 1 & 0 & 3 & 0 & 0 & 2 & 0 & 1 & 1 & 0 & ? & 0 & 1 & 0 \\ 0 & 0 & 1 & 1 & ? & 0 & ? & 3 & 0 & 0 & 1 & 1 & ? & 1 & 0 & ? & 1 & 2 & 1 \\ 1 & 0 & 1 & 1 & 1 & 0 & 0 & 3 & 0 & 1 & 1 & 1 & 0 & ? & ? & 1 & 1 & 1 & 0 \& 1\end{array}$

$\begin{array}{rllllllllllllllllll}1 & 0 & 1 & 1 & 1 & 0 & 0 & 3 & 0 & 1 & 1 & 1 & 0 & ? & ? & 1 & 1 & 1 & 0 \& 1 \\ 0 & 0 & 1 & ? & 1 & ? & 0 & 3 & 0 & 0 & 1 & 1 & 1 & 1 & 0 & 0 & 1 & 1 & 1 \\ 0 & 0 & 1 & ? & 1 & ? & 0 & 2 & ? & 0 & 2 & 0 & 1 & 0 & 0 & 0 \& 1 & 1 & 1 & 0\end{array}$

$0 \& 1$
1
0

$\begin{array}{lllllllllllllllllll}0 & 0 & 1 & 1 & 1 & 2 & 2 & 0 & 0 & 1 & 1 & 0 & 0 & 1 & 0 & 0 & 0 & 1 & 0 \\ 0 & 0 & 0 & ? & 1 & ? & 0 & 1 & 0 & 0 & 0 & 0 & 0 & 1 & 0 & ? & 0 & 1 & 0\end{array}$

$\begin{array}{lllll}0 & 0 & 1 & \text { ? ? }\end{array}$

$\begin{array}{lllll}1 & 0 & 0 & 2 & 2 \\ 0 & 0 & 1 & 1 & ?\end{array}$

0

$\begin{array}{ll}0 & 0 \\ 0 & 0\end{array}$

$\begin{array}{lllllllll}0 & 0 & 1 & 1 & 1 & 0 & 0 & 3 & 0\end{array}$

$\begin{array}{llllll}0 & 0 & 1 & 2 & 0\end{array}$

$\begin{array}{lllll}0 & 0 & 1 & ? & 1\end{array}$

$\begin{array}{lll}1 & 1 & 3 \\ 1 & 1 & 2\end{array}$

00

$$
\text { ? }
$$

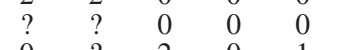

0
0

$\begin{array}{lll}0 & 1 \\ 0 & 1\end{array}$

$\begin{array}{llllll}1 & 0 & 0 & 1 & 1 \\ 1 & 0 & 1 & 0 & 2\end{array}$

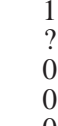


$\begin{array}{llllllllllllllllllllllll}20 & 21 & 22 & 23 & 24 & 25 & 26 & 27 & 28 & 29 & 30 & 31 & 32 & 33 & 34 & 35 & 36 & 37 & 38 & 39 & 40 & 41 & 42 & 43\end{array}$

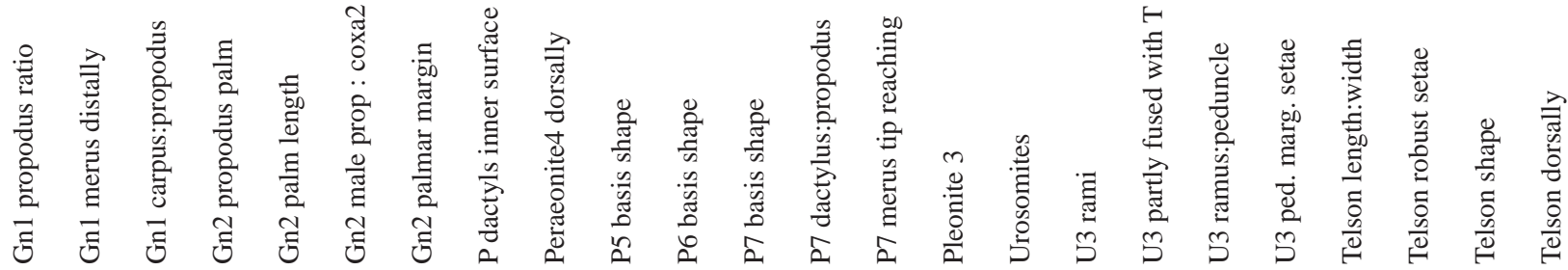
$\begin{array}{lllllllllllllllllllllllllll} & 0 & 0 & 0 & 0 & 0 & 0 & 0 & 0 & 0 & 0 & 0 & 0 & 0 & 0 & 0 & 0 & 0 & 0 & 0 & 0 & 0 & 0 & 0\end{array}$ $\begin{array}{llllllllllllllllllllllllllllll}0 & 0 & 2 & 0 & 0 & 0 & 0 & 0 & 0 & 0 & 0 & 0 & 1 & 0 & 0 & 0 & 1 & 0 & 1 & 1 & 0 & 1 & 0 & 0 \\ 1 & 0 & 0 & 0 & 0 & 0 & 0 & 0 & 0 & 0 & 0 & 0 & 1 & 1 & 0 & 0 & 0 & 0 & 0 & 1 & 1 & 1 & 0 & 0\end{array}$ $\begin{array}{llllllllllllllllllllllllllll}0 & 0 & 1 & 0 & 0 & 0 & 0 & 0 & 0 & 0 & 0 & 0 & 1 & 1 & 0 & 0 & 0 & 0 & 0 & 1 & 1 & 1 & 0 & 0\end{array}$ $\begin{array}{llllllllllllllllllllllllllllll}0 & 0 & ? & 0 & 1 & 0 & 0 & 0 & 1 & 2 & 0 & 1 & 0 & 1 & 0 & 0 & 0 & 0 & 1 & 1 & 1 & 1 & 0 & 0\end{array}$ $\begin{array}{llllllllllllllllllllllllll}? & 0 & ? & 1 & 0 & 1 & 0 & 0 & 1 & 3 & 2 & 3 & 0 & 0 & 0 & 0 & 0 & 0 & 1 & 1 & 0 & 1 & 0 & 0 \\ 0 & 0 & 0 & 0 & 1 & 0 & 0 & 0 & 0 & 3 & ? & 0 & 1 & 1 & 0 & 0 & 1 & 0 & ? & ? & 0 & 0 & 0 & 0\end{array}$ $\begin{array}{lllllllllllllllllllllllllll}0 & 0 & 1 & 0 & 0 & ? & 1 & 0 & 1 & 3 & 2 & 3 & 1 & 0 & 0 & 0 & 1 & 0 & 0 & 1 & 1 & 0 \& 1 & 0 & 0\end{array}$ $\begin{array}{llllllllllllllllllllllllllll}1 & 1 & 1 & 0 & 1 & 1 & 1 & 0 & 0 & 3 & 0 & 0 & 1 & 1 & 0 & 0 & 1 & 0 & 0 & 0 & 0 & 0 & 0 & 0 \\ 0 & 0 & 1 & 0 & 0 & 0 & 0 & 0 & 0 & 3 & 2 & 1 & 0 & 0 & 0 & 0 & 1 & 0 & 0 & 0 & 1 & 0 & 0 & 0\end{array}$ $\begin{array}{lllllllllllllllllllllllllllll}0 & 0 & 0 & 0 & 0 & 0 & 0 & 0 & 1 & 3 & 1 & 0 & 1 & 1 & 0 & 0 & 1 & 0 & 0 & 1 & 0 & 0 & 0 & 0\end{array}$ $\begin{array}{llllllllllllllllllllllll}1 & 1 & 1 & 1 & 0 & 0 & 1 & 0 & 0 & 3 & 1 & 2 & 2 & 1 & 0 & 0 & 1 & 0 & 0 & 0 & 1 & 0 & 0 & 0 \\ 1 & ? & 1 & 0 & 0 & 1 & 1 & 0 & 0 & ? & ? & 0 & 0 & 2 & 0 & 0 & 1 & 0 & 1 & 0 & ? & 0 & 0 & 0\end{array}$ $\begin{array}{lllllllllllllllllllllllllll}0 & 1 & 0 & 0 & 0 & 0 & 0 & 0 & 0 & 3 & 0 & 0 & 0 & 2 & 0 & 0 & 1 & 0 & 0 & 0 & 1 & 0 & 0 & 0\end{array}$ $\begin{array}{lllllllllllllllllllllllllllll}0 & 1 & 2 & 1 & 0 & 0 & 1 & 0 & 0 & 3 & 0 & 0 & 1 & 2 & 0 & 0 & 1 & 0 & 1 & 0 & 1 & 0 & 0 & 0 \\ 0 & 0 & 1 & 0 & 0 & ? & 0 & 0 & 0 & 3 & 0 & 0 & 0 & 2 & 0 & 0 & 1 & 0 & 0 & 0 & 1 & 1 & 0 & 0\end{array}$ $\begin{array}{llllllllllllllllllllllllllll}0 & 0 & 0 & 0 & 0 & 0 & 0 & 0 & 0 & 3 & 2 & 3 & 1 & 0 \& 1 & 0 & 0 & 1 & 0 & 1 & 0 & 1 & 1 & 0 & 0\end{array}$ $\begin{array}{lllllllllllllllllllllllllllll}0 & 1 & 2 & 1 & 0 & 0 & 1 & 0 & 0 & 3 & 2 & 2 & 1 & 1 & 0 & 0 & 1 & 0 & 0 & 0 & 0 & 0 & 0 & 0\end{array}$ $\begin{array}{llllllllllllllllllllllllllllll}0 & 1 & 1 & 0 & 0 & 1 & 1 & 0 & 0 & 3 & 2 & 2 & 0 & 1 & 0 & 0 & 1 & 0 & 0 & 0 & 1 & 1 & 0 & 0 \\ 1 & 0 & 1 & 0 & 1 & ? & 0 & 0 & 0 & 3 & 0 & 0 & 0 & 0 & 0 & 0 & 1 & 0 & 1 & 0 & 0 & 0 & 0 & 0\end{array}$ $\begin{array}{lllllllllllllllllllllllllll}0 & 0 & 0 & 0 & 1 & ? & 0 & 0 & 0 & 3 & 0 & 0 & 1 & 1 & 0 & 0 & 1 & 0 & ? & 0 & ? & 0 & 0 & 0\end{array}$ $\begin{array}{llllllllllllllllllllllllllllll}0 & 0 & 0 & 1 & 0 & 0 & 1 & 0 & 0 & 3 & 0 & 0 & 1 & 1 & 0 & 0 & 1 & 0 & 0 & 1 & 1 & 1 & 0 & 0\end{array}$ $\begin{array}{cccccccccccccccccccccccc}1 & 1 & 0 & 1 & 0 & 0 & 0 \& 1 & 0 & 0 & 3 & 0 & 0 & 1 & 2 & 0 & 0 & 1 & 0 & 1 & 0 & 0 & 0 & 0 & 0 \\ 0 & 1 & 1 & 0 & 0 & ? & 1 & 0 & 0 & 3 & 2 & 3 & 0 & 1 & 0 & 0 & 1 & 0 & 0 & 1 & 1 & 1 & 0 & 0\end{array}$ $\begin{array}{llllllllllllllllllllllllllllll}1 & 0 & 0 & 0 & 0 & 0 & 0 & 0 & 0 & 3 & 1 & 2 & 0 & 0 & 0 & 0 & 1 & 0 & 0 & 0 & 1 & 1 & 0 & 0\end{array}$ $\begin{array}{llllllllllllllllllllllllllll}0 & 0 & 0 & 0 & 0 & ? & 0 & 0 & 0 & 3 & 2 & 3 & 0 & 0 & 0 & 0 & 1 & 0 & 0 & 1 & 1 & 0 & 0 & 0\end{array}$ $\begin{array}{llllllllllllllllllllllllllllll}0 & 1 & 1 & 0 & 1 & 1 & 1 & 0 & 0 & 3 & 0 & 0 & 1 & 2 & 0 & 0 & 1 & 0 & 1 & 0 & 1 & 0 & 0 & 0\end{array}$ $\begin{array}{llllllllllllllllllllllllll}1 & 0 & 0 & 0 & 0 & ? & 1 & 0 & 0 & 3 & 0 & 0 & 1 & ? & 0 & 0 & 1 & 0 & 0 & 0 & ? & 0 & 0 & 0 \\ 0 & 0 & 2 & 1 & 0 & 0 & 1 & 0 & 0 & 3 & 0 & 0 & 1 & 2 & 0 & 0 & 1 & 0 & 1 & 0 & 1 & 0 & 0 & 0\end{array}$ $\begin{array}{llllllllllllllllllllllllll}0 & 0 & 0 & 0 & 1 & 0 & 0 & 0 & ? & 3 & 0 & 0 & 1 & 1 & 0 & 0 & 1 & 0 & 0 & 0 & ? & 0 & 0 & 0\end{array}$ $\begin{array}{lllllllllllllllllllllllllllll}1 & 0 & 2 & 1 & 1 & 1 & 1 & 0 & 0 & 1 & 0 & 0 & 0 & 2 & 0 & 0 & 1 & 0 & 1 & 0 & 1 & 0 & 0 & 0 \\ 0 & 0 & 2 & 0 & 0 & 1 & 1 & 0 & 0 & 1 & 0 & 0 & 0 & 1 & 0 & 0 & 1 & 0 & 0 & 0 & 1 & 0 & 0 & 0\end{array}$ $\begin{array}{llllllllllllllllllllllllllllll}0 & 0 & 2 & 1 & 0 & 0 & 0 & 0 & 0 & 2 & 0 & 0 & 1 & 2 & 0 & 0 & 1 & 0 & 0 & 0 & 1 & 0 & 0 & 0\end{array}$ $\begin{array}{lllllllllllllllllllllllllll}1 & 1 & 1 & 0 & 0 & 0 & 1 & 0 & 0 & 3 & 0 & 0 & 0 & 2 & 0 & 0 & 1 & 0 & 1 & 0 & 0 & 1 & 0 & 0\end{array}$ $\begin{array}{llllllllllllllllllllllllllllll}1 & 1 & 2 & 0 & 1 & 1 & 1 & 0 & 0 & 3 & 0 & 0 & 1 & 1 & 0 & 0 & 1 & 0 & 1 & 0 & 0 & 0 & 0 & 0 \\ 1 & 0 & 0 & 0 & 0 & 0 & 0 & 0 & 0 & 3 & 0 & 0 & 1 & 1 & 0 & 0 & 1 & 0 & 0 & 0 & 0 & 1 & 0 & 0\end{array}$ $\begin{array}{llllllllllllllllllllllllll}1 & 1 & 0 & 0 & 1 & 1 & 0 & 0 & 0 & 3 & 0 & 0 & 1 & 2 & 0 & 0 & 1 & 0 & 0 & 0 & 0 & 0 & 0 & 0\end{array}$ $\begin{array}{cccccccccccccccccccccccc}1 & 0 \& 1 & 2 & 0 & 0 & 0 & 0 & 0 & 0 & 3 & 0 & 0 & 1 & 2 & 0 & 0 & 1 & 0 & 0 & 1 & 1 & 0 & 0 & 0 \\ 0 & 1 & 1 & 0 & 0 & 0 & 1 & 0 & 0 & 3 & 0 & 0 & 1 & 2 & 0 & 0 & 1 & 0 & 0 & 1 & 1 & 1 & 0 & 0\end{array}$ $\begin{array}{lllllllllllllllllllllllllllll}0 & 0 & 1 & 0 & 0 & ? & 1 & 0 & 0 & 1 & 0 & 0 & 1 & 1 & 0 & 0 & 1 & 0 & 0 & 0 & 1 & 0 & 0 & 0\end{array}$ $\begin{array}{lllllllllllllllllllllllllll}1 & 1 & 1 & 0 & 0 & 0 & 1 & 0 & 0 & 1 & 0 & 0 & 1 & 2 & 0 & 0 & 1 & 0 & 1 & 0 & 1 & 0 & 0 & 0 \\ 0 & 1 & 2 & 0 & 0 & 1 & 1 & 0 & 0 & 1 & 0 & 0 & 1 & 1 & 0 & 0 & 1 & 0 & 1 & 0 & 1 & 0 & 0 & 0\end{array}$ $\begin{array}{lllllllllllllllllllllllllllll}0 & 0 & 0 & 0 & 0 & 0 & 0 & 0 & 0 & 3 & 2 & 3 & 0 & 0 & 0 & 0 & 1 & 0 & 1 & 0 & 1 & 0 & 0 & 0\end{array}$ $\begin{array}{llllllllllllllllllllllllllll}0 & 0 & 2 & 0 & 1 & ? & 1 & 0 & 0 & 3 & 0 & 0 & 1 & 2 & 0 & 0 & 1 & 0 & 1 & 0 & 1 & 0 & 0 & 0 \\ 0 & 0 & 0 & 1 & 0 & ? & 0 & 1 & 2 & 3 & 2 & 3 & 0 & 1 & 1 & 0 & 1 & 0 & 0 & 0 & 0 & 0 & 0 & 0\end{array}$ $\begin{array}{llllllllllllllllllllllllllll}1 & 1 & 0 & 1 & 0 & 1 & 0 & ? & 2 & 3 & 2 & 3 & 1 & 0 & 0 & 1 & 1 & 1 & 0 & 1 & 1 & 1 & 2 & 1\end{array}$

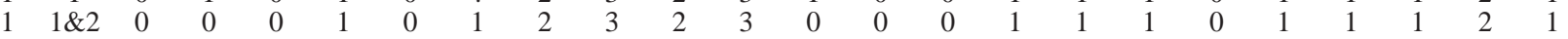
$\begin{array}{llllllllllllllllllllllllllllll}0 & 0 & 0 & 1 & 0 & 1 & 0 & 0 & 2 & 3 & 2 & 3 & 1 & 0 & 1 & 1 & 1 & 1 & 1 & 1 & 1 & 1 & 1 & 0\end{array}$ $\begin{array}{llllllllllllllllllllllllllllll}0 & 1 & 0 & 0 & 1 & 1 & 0 & 1 & 0 & 2 & 2 & 2 & 0 & 0 & 0 & 0 & 1 & 1 & 0 & 1 & 1 & 1 & 0 & 0 \\ 1 & 0 & 0 & 0 & 0 & 1 & 0 & 1 & 2 & 3 & 2 & 3 & 0 & 0 & 1 & 1 & 1 & 1 & 0 & 0 & 0 & 1 & 1 & 0\end{array}$ $\begin{array}{llllllllllllllllllllllllllll}1 & 0 & 0 & 0 & 0 & 1 & 0 & 1 & 2 & 3 & 2 & 3 & 0 & 0 & 1 & 1 & 1 & 1 & 0 & 0 & 0 & 1 & 1 & 0 \\ 1 & 1 & 0 & 2 & 0 & 0 & 0 & 0 & 1 & 3 & 2 & 3 & 0 & 0 & 0 & 1 & 1 & 1 & 0 & 0 & 0 & 1 & 1 & 1\end{array}$ $\begin{array}{llllllllllllllllllllllllllll}1 & 1 & 1 & 0 & 0 & 0 & 0 & 0 & ? & 3 & 2 & 3 & 0 & 2 & 1 & 0 & 1 & 1 & 0 & 0 & 0 & 1 & 1 & 0\end{array}$ $\begin{array}{llllllllllllllllllllllllll}1 & 0 & 2 & 0 & 0 & 0 & 0 & 2 & 3 & 2 & 3 & 1 & 1 & 0 & 1 & 1 & 0 & 0 & 1 & ? & 1 & 0 & 0 \\ 0 & 0 \& 1 & 0 & 2 & 0 & 0 & 0 & 1 & 1 & 3 & 2 & 3 & 1 & 1 & 1 & 1 & 1 & 1 & 1 & 1 & 0 & 1 & 1 & 0\end{array}$ $\begin{array}{cccccccccccccccccccccccc}0 & 1 & 0 & 2 & 0 & 0 & 0 & 1 & 1 & 3 & 2 & 3 & 0 & 0 & 1 & 1 & 1 & 1 & 1 & 1 & 1 & 1 & 1 & 0 \\ 1 & 1 & 0 & 2 & 0 & 0 & 0 & 1 & 1 & 3 & 2 & 3 & 0 & 0 & 0 & 1 & 1 & 1 & 1 & 1 & 1 & 1 & 1 & 0\end{array}$ $\begin{array}{cccccccccccccccccccccccc}1 & 1 & 0 & 2 & 0 & 0 & 0 & 1 & 1 & 3 & 2 & 3 & 0 & 0 & 0 & 1 & 1 & 1 & 1 & 1 & 1 & 1 & 1 & 0 \\ 1 & 1 & 0 & 1 \& 2 & 0 & 0 & 0 & 0 & 0 \& 1 & 3 & 2 & 3 & 1 & 0 & 1 & 1 & 1 & 1 & 0 & 0 & 1 & 1 & 2 & 1\end{array}$ $\begin{array}{lllcllllllllllllllllllllll}1 & 1 & 0 & 0 & 0 & 0 & 0 & 0 & 2 & 3 & 2 & 3 & 0 & 1 & 1 & 1 & 1 & 1 & 0 & 0 & 0 & 1 & 1 & 1\end{array}$ $\begin{array}{lllllllllllllllllllllllllll}0 & 1 & 1 & 0 & 0 & 0 & 0 & 0 & 2 & 3 & 2 & 3 & 0 & 0 & 1 & 1 & 1 & 1 & 0 & 0 & 1 & 1 & 2 & 1 \\ 1 & 0 & 1 & 0 & 1 & 0 & 1 & 0 & 2 & 3 & 1 \& 2 & 2 & 1 & 1 & 1 & 1 & 1 & 1 & 0 & 1 & 0 & 1 & ? & 0\end{array}$ 
well have evolved independently in different lineages, and the separation of articles is sometimes unclear.

The initial attempts towards understanding phylogenetic relationships of the stenothoid amphipods were started by the first author more than a decade ago in Verona and Sydney, and were continued off and on over the years in Hamburg, Tromsoe, Melbourne and at home in Bonn. The final study presented here results from a recent collaboration between the authors in Hannover. Our aim is to throw light on the phylogenetic relationships within the family Stenothoidae by cladistic analysis of morphological characters. We hope this will encourage detailed follow-up investigations by ourselves and others of these groups of amphipods, often found as symbionts of hydroids, sponges, ascidians and also sea anemones or crabs, and also inhabiting interstitial habitats. Rigorous phylogenetic analysis will undoubtedly contribute to a deeper understanding of the taxonomy, biology, ecology and behaviour of these taxa (see Krapp-Schickel, 2006b, c).

\section{Material and methods}

\section{Choice of taxa}

We chose an unspecialized representative of Gammarus as out-group, generally considered to be a plesiomorphic amphipod. We added a few representatives from Amphilochidae, Cyproideidae and Cressidae, all consisting of species with a number of the same (presumed) apomorphies as the Stenothoidae, and also with a similar way of life.

Taxa in the in-group are the type species of all stenothoid genera; in a few cases, where a genus is morphologically very diverse, additional species were added. The characters used in this analysis are based on the generic diagnoses as given by Barnard and Karaman (1991). In addition, we included a number of further characters, mainly from the urosome, a region treated by Barnard and Karaman (op. cit.) in less detail than warranted.

We used two alternative data sets for our phylogenetic analyses. In the initial matrix (A) we included all stenothoid genera, also those poorly described, as well as the types of nominal genera that traditionally had been synonymized. This matrix was composed of 61 taxa and 43 characters (Fig. 1). As it turned out that this large matrix led to intolerably long compution times when choosing the combination of optimal search parameters, we set up a second matrix (B), in which 20 taxa were excluded, while the number of characters remained the same (Fig. 6).

\section{Cladistic analyses}

A) Initial, large matrix: The data set was analysed using the parsimony criterion available in PAUP* version 4.0b10.

For the initial matrix A with 61 taxa (Fig. 1), we used the following heuristic search options: Multistate taxa were interpreted as polymorphism; starting tree(s) obtained via stepwise addition; addition sequence $=$ simple $($ reference taxon $=$ Gammarus sp.); number of trees held at each step during stepwise addition $=1$; branch-swapping algorithm = tree-bisection-reconnection (TBR); steepest descent option not in effect; 'MaxTrees' setting = 7000 (will not be increased); zero-length branches were not collapsed; 'MulTrees' option was in effect; topological constraints were not enforced. We conducted two runs for this initial large matrix.

a) In the first 'unconstrained run', all characters were of type 'unordered' and equally weighted.

b) Subsequently, we analysed character state transformations in PAUP and MacClade 4.06 (Madisson and Madisson, 2003) and applied constraints to particular transformations that we considered highly unlikely. These constrained transformations, e.g., 'ordered', 'irreversible' and user-defined state changes, were then analysed in a second 'constrained run' (see Table 1 and following section).

B) Reduced matrix: Since the chosen heuristic search options for the initial matrix do not guarantee to find all maximum parsimonious trees (MPTs), we conducted two further analyses with a reduced data set $\mathrm{B}$ : we excluded 20 species from the initial matrix (composed of 61 taxa), eliminating non-type species of currently valid genera; in addition, we also reduced the out-group to Gammarus sp. and a single amphilochid, Gitana. For this smaller matrix (composed of 41 taxa), the 43 characters of the initial matrix were left unchanged (Fig. 6).

Again, we conducted two runs:

c) we conducted a heuristic search defining one more irreversible character and changing the weight 
Table 1. Overview of trees resulting from analytical and methodological alternatives used in this study.

\begin{tabular}{lllll}
\hline & Initial matrix (61 taxa) & & \multicolumn{2}{l}{ Reduced matrix (41 taxa) } \\
\cline { 2 - 5 } & Unconstrained run & Constrained run & Constrained run & Unconstrained optimized run \\
\hline $\begin{array}{l}\text { Parsimony } \\
\text { analyses }\end{array}$ & Strict consensus & Majority Rule consensus & Strict consensus & Majority Rule consensus \\
of 269 trees (Fig. 4) & of 7000 trees (Fig. 5) & of 36 trees (Fig. 7) & of 2393 trees (Fig. 9) \\
\hline
\end{tabular}

from 1 to 5 in another character, but otherwise using the same options and parameters as for the initial constrained analysis (b).

d) In this last heuristic search, we changed some of the options as follows: Addition sequence $=$ random; number of replicates $=20$; starting seed $=$ 67559391; random trees (not just addition sequence) used as starting point; number of trees held at each step during stepwise addition $=7$; steepest descent option in effect. This combination of search parameters is more likely to find all MPTs (see Table 1).

\section{Characters and their states}

For both the initial and reduced set of taxa, we used 43 morphological characters, all of which were parsimony-informative in all analyses. Character states are given in square brackets.

Head:

1. Antenna 1, shape of article 1: [0] ordinary; [1] nasiform (see Fig. 2)

2. Antenna 1, shape of article 2: [0] normal; [1] inflated-nasiform (see Fig. 2)

3. Accessory flagellum: [0] with more than 1 article; [1] absent or 1 article

4. Length ratio antenna 1 - antenna 2, male: [0] antenna 1 longer than antenna 2; [1] subequal; [2] antenna 1 shorter than antenna 2

5. Length ratio antenna 1 - antenna 2, female: [0] antenna 1 longer than antenna 2; [1] subequal; [2] antenna 1 shorter than antenna 2

6. Antenna 1, length ratio article 1 - article 2, male: [0] article 1 longer than article 2; [1] articles subequal; [2] article 1 shorter than article 2

7. Antenna 1, length ratio article 1 - article 2, female: [0] article 1 longer than article 2; [1] articles subequal; [2] article 1 shorter than article 2

8. Mandible, number of palp articles: [0] = 3; [1] $=2 ;[2]=1 ;[3]=0$
9. Maxilliped, inner plate well - separated: [0] yes; [1] no

10. Maxilliped, length ratio: [0] inner plate longer or equal half ischium; [1] inner plate shorter than half ischium

11. Maxilliped, length ratio: [0] outer plate longer/ subequal half length of merus; [1] outer plate shorter than half length of merus; [2] outer plate absent

12. Maxilla 1, number of palp articles: [0] = 2; [1] $=1$

13. Maxilla 2, arrangement of lobes: [0] two lobes of similar length parallel to each other = ,tandem position“; [1] parallel, but inner lobe much shorter; [2] outer lobe riding on inner lobe (see Fig. 2).

Gnathopods, coxal plates:

14. Coxa 4: [0] longer than wide; [1] subequal, or wider than long

15. Coxa 4, ventro-posterior margin: [0] regularly rounded; [1] ventrally straight, parallel to dorsal margin of widened somite

16. Gnathopod 2, propodus shape similar in male and female: [0] yes; [1] no

17. Gnathopod $1+2$ similar in shape: [0] yes; [1] no

18. Gnathopod $1+2$ size of propodi: [0] similar; [1] gnathopod 2 propodus shorter than twice the length of gnathopod 1 propodus; [2] gnathopod 2 equal or longer than twice the length of gnathopod 1 propodus

19. Gnathopod 1, propodus: [0] subchelate, rectipalmate or parachelate; [1] simple

20. Gnathopod 1, propodus, ratio length - width: [0] more than twice as long as wide; [1] twice as long as wide, or less than twice as long

21. Gnathopod 1, merus distally free = merochelate (see Fig. 3): [0] no; [1] yes

22. Gnathopod 1: [0] carpus shorter than propodus; [1] subequal; [2] carpus clearly longer than propodus 

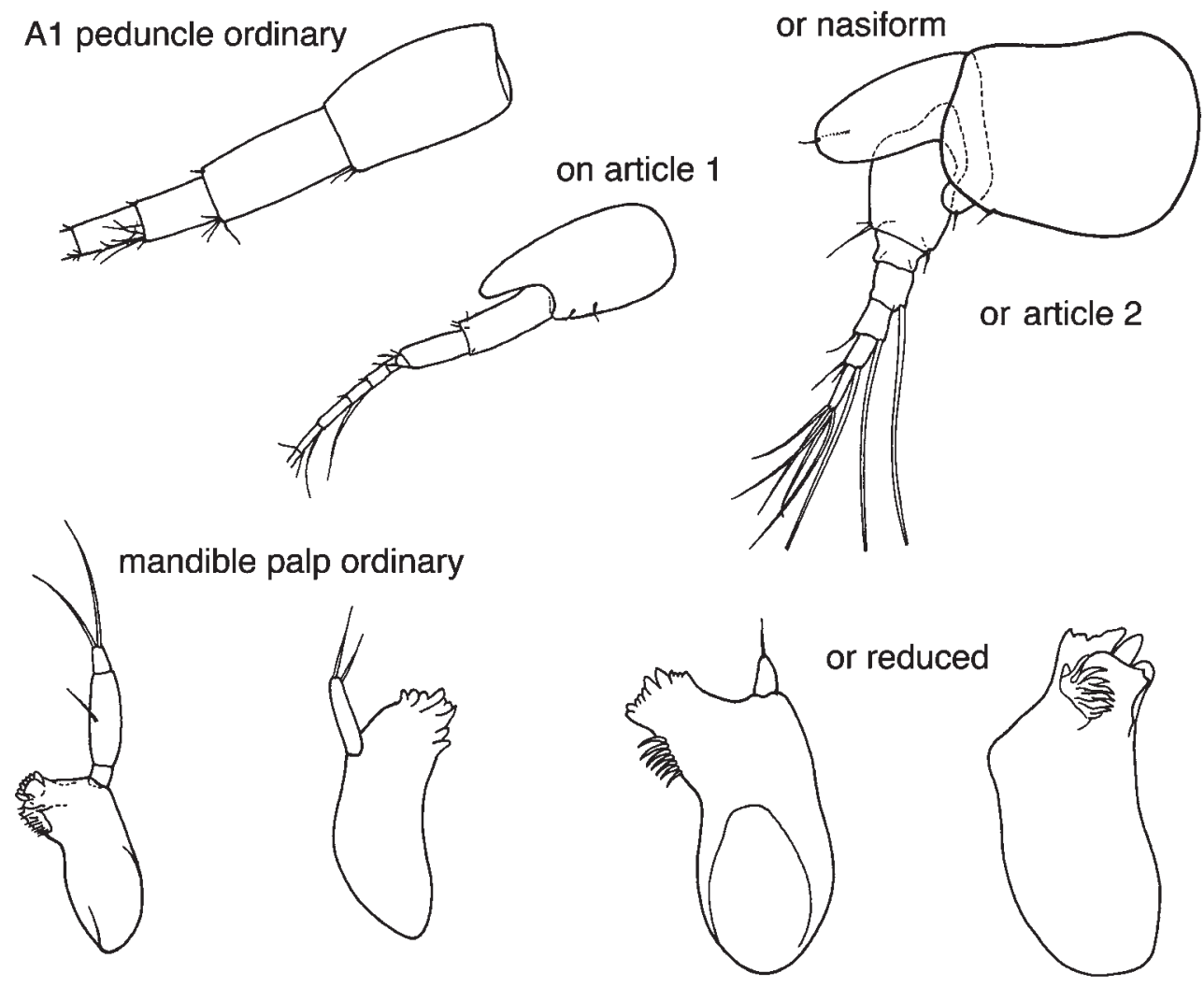

maxilla 1 palp with 1 or 2 articles

\section{maxilliped inner plates fused outer plate vanishing}
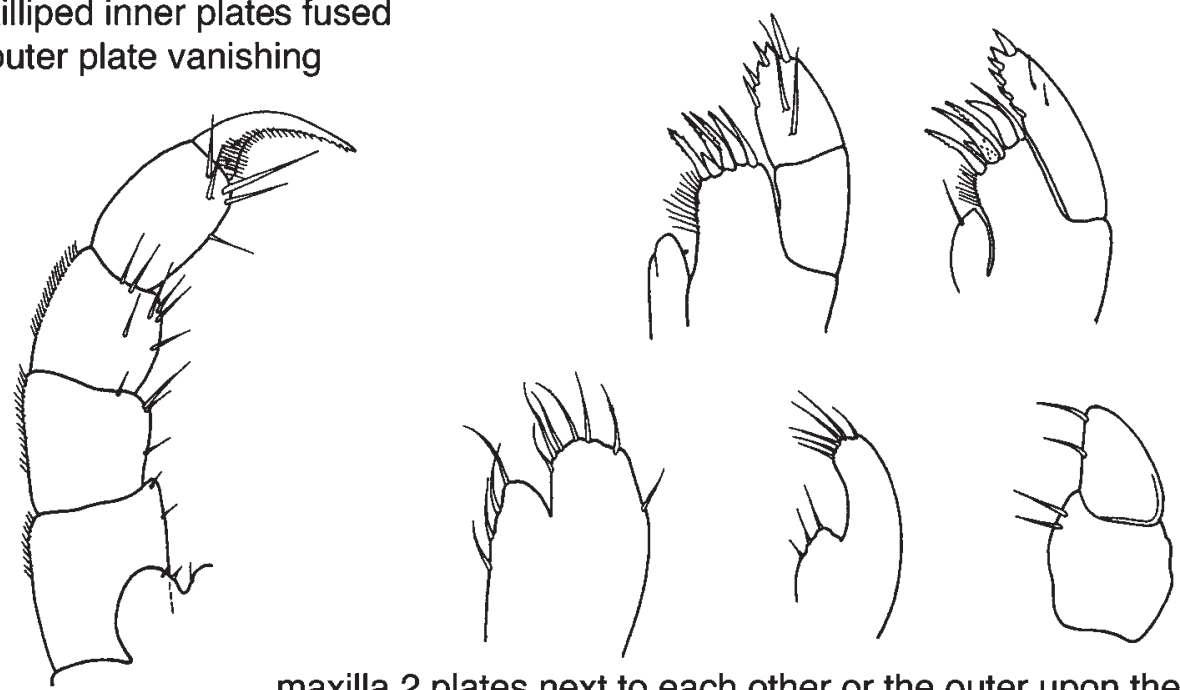

maxilla 2 plates next to each other or the outer upon the inner

Fig. 2. Main characters used for cladistic analysis of Stenothoidae: (1) Antenna 1, shape of article 1: [0] ordinary; [1] nasiform. (2) Antenna 1, shape of article 2: [0] normal; [1] inflated-nasiform. (8) Mandible, number of palp articles: [0] = 3; [1] = 2; [2] = 1; [3] = 0. (10) Maxilliped, length ratio: [0] inner plate longer or equal half ischium; [1] inner plate shorter than half ischium. (11) Maxilliped, length ratio: [0] outer plate longer/subequal half length of merus; [1] outer plate shorter than half length of merus; [2] outer plate absent. (12) Maxilla 1, number of palp articles: [0] = 2; [1] = 1. (13) Maxilla 2, arrangement of lobes: [0] two lobes of similar length parallel to each other = "tandem position"; [1] parallel, but inner lobe much shorter; [2] outer lobe riding on inner lobe. 

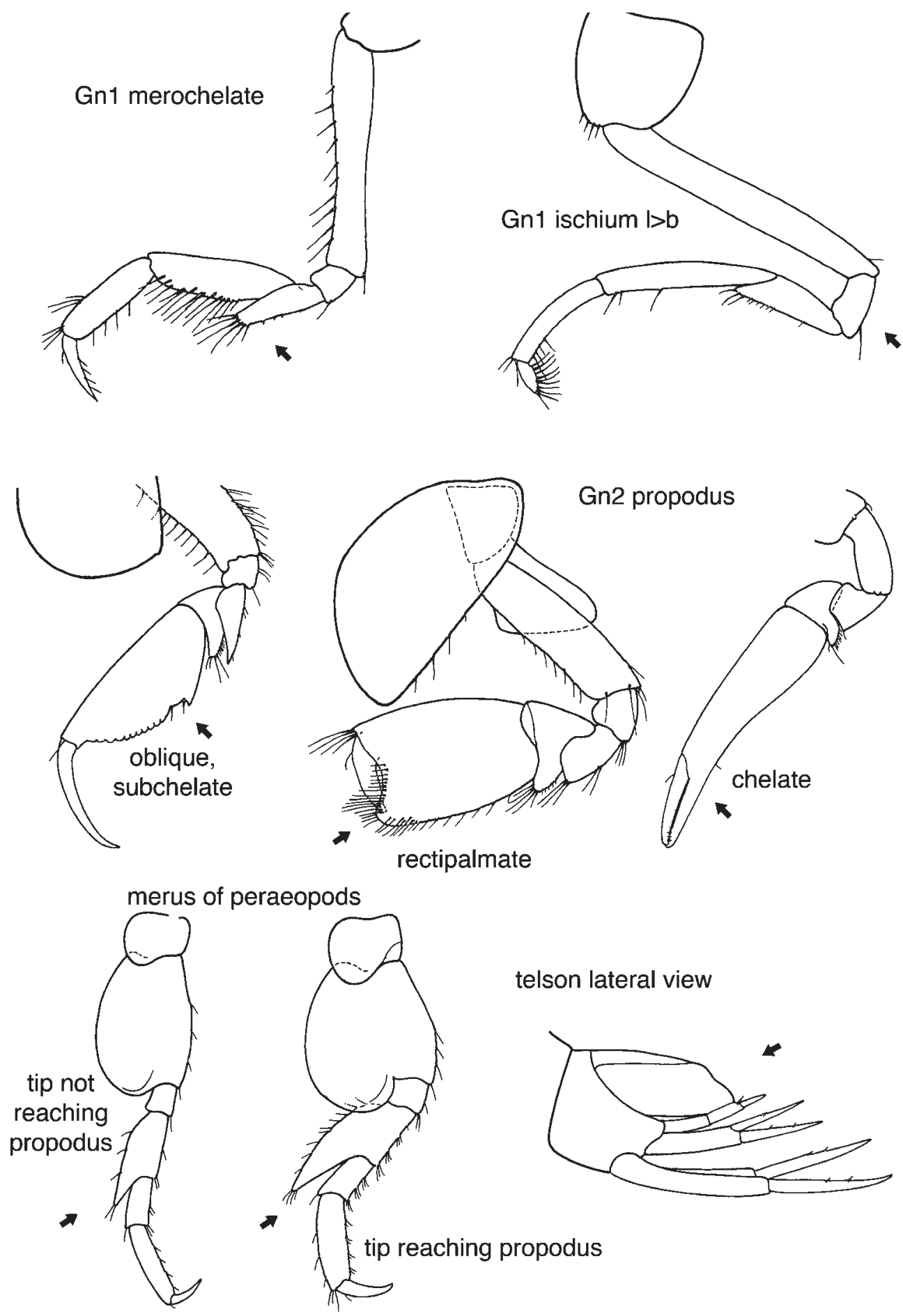

Fig. 3. Main characters used for cladistic analysis of Stenothoidae continued: (21) Gnathopod 1, merus distally free = merochelate (see Fig. 3): [0] no; [1] yes. (24) Gnathopod 2, palm: [0] less than 150\% of remaining propodal posterior margin; [1] equal to or more than 150\% of remaining propodal posterior margin. (33) Peraeopod 7, length of merus: [0] unexpanded; [1] lengthened to less than half carpus, or reaching half of carpus; [2] reaching more than half carpus. (42) Telson, shape: [0] horizontal, dorsoventrallly flat = depress, thin and flappable; [1] vertically inflated, three-dimensional (proboliscid stenothoid); [2] with vertical area strongly enlarged, laterally flat $=$ compress. 


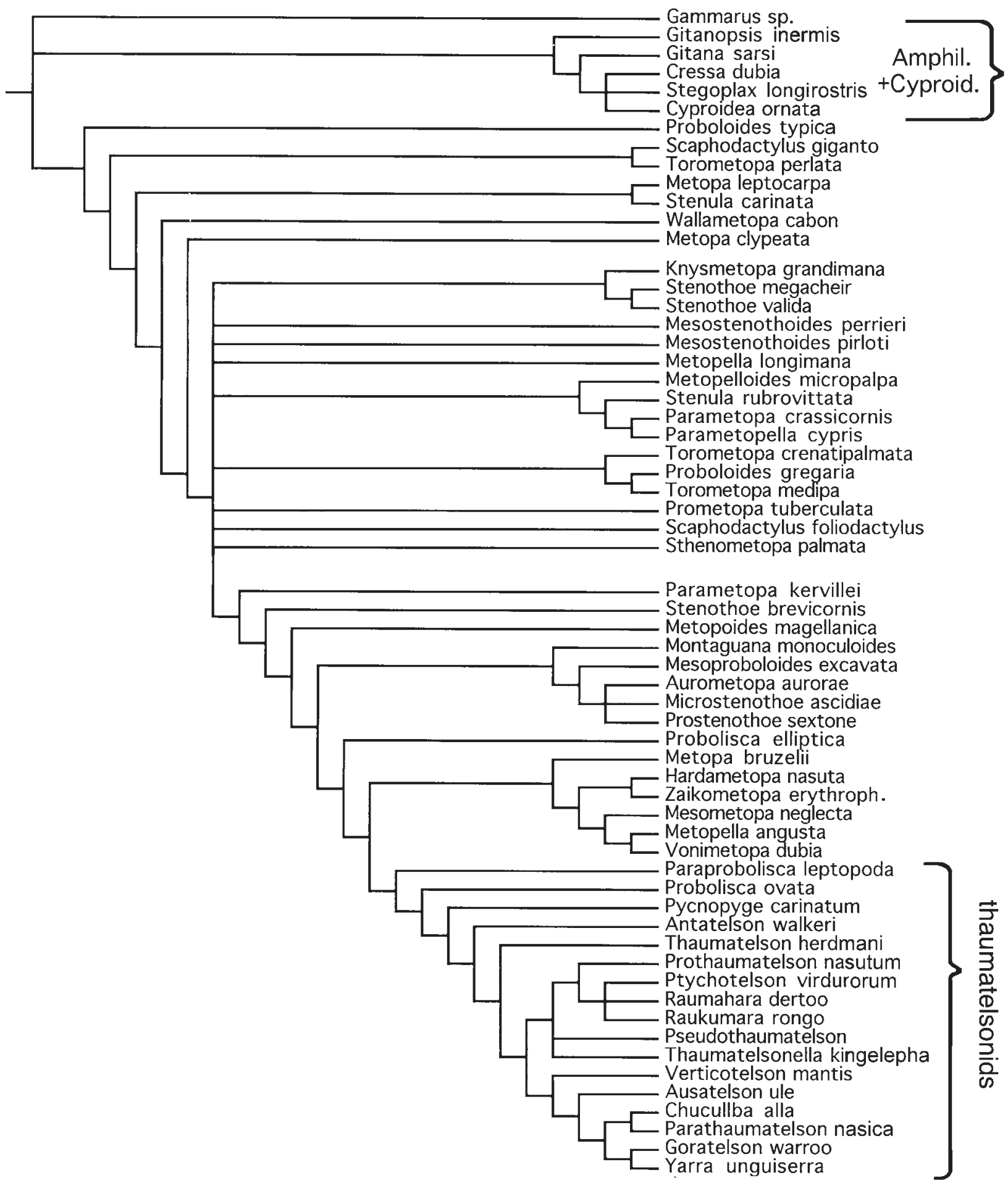

Fig. 4. Unconstrained analysis of 61 species and 43 characters: strict consensus tree of 269 trees; length $=429$ (sum of min. possible lengths $=82$; sum of max. possible lengths $=828$; $\mathrm{CI}=0.191, \mathrm{RI}=0.535, \mathrm{RC}=0.102, \mathrm{HI}=0.851$. 


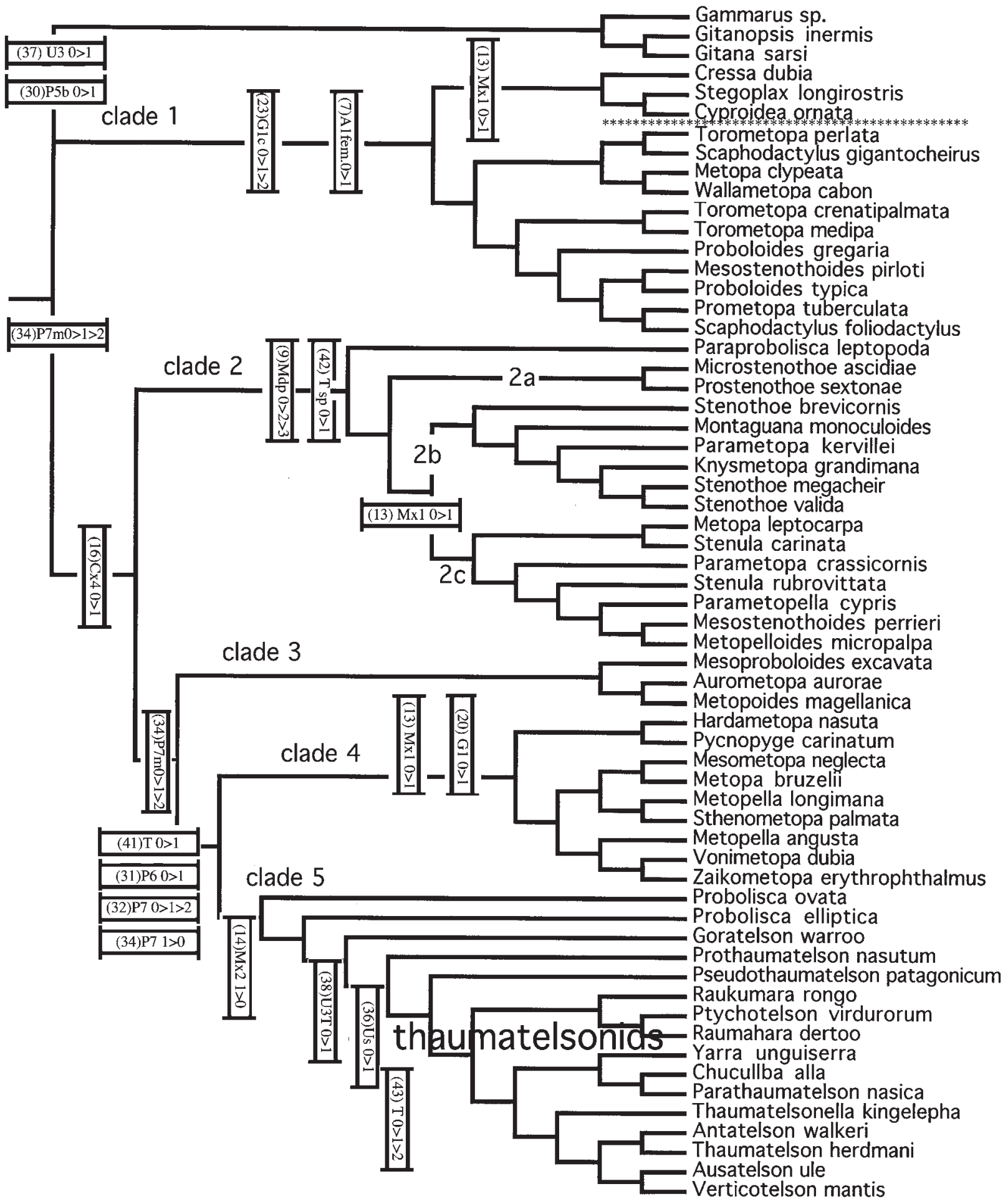

Fig. 5. Constrained analysis of 61 species and 43 characters: 50\% Majority Rule consensus tree of 7000 trees; length = 435 (sum of min. possible lengths $=82$; sum of max. possible lengths $=828$; $\mathrm{CI}=0.189, \mathrm{RI}=0.527, \mathrm{RC}=0.099, \mathrm{HI}=0.853$. 
23. Gnathopod 2, palm of propodus: [0] absent or oblique; [1] transverse = rectipalmate; [2] acute = parachelate

24. Gnathopod 2, palm: [0] less than $150 \%$ of remaining propodal posterior margin; [1] equal to or more than $150 \%$ of remaining propodal posterior margin

25. Gnathopod 2, male, length of propodus compared to length of coxa 2: [0] propodus equal or shorter than coxa 2; [1] propodus longer than coxa 2

26. Gnathopod 2, palmar margin: [0] smooth; [1] serrate and/or deeply incised

Peraeon:

27. Peraeopods, inner surface of dactyls: [0] smooth; [1] comb-shaped

28. Peraeonite 4, dorsal extension: [0] less than twice the extension of segment 3; [1] double extension of segment 3; [2] more than twice extension of segment 3 (see Fig. 10)

29. Peraeopod 5, basis: [0] widened and ovoid rounded; [1] unequally widened; [2] rectangularly widened; [3] recto - linear, narrow

30. Peraeopod 6, basis: [0] regularly rounded; [1] rectangularly widened; [2] linear

31. Peraeopod 7, basis: [0] regularly rounded; [1] unequally widened; [2] rectangularly widened; [3] linear

32. Peraeopod 7, length of dactylus: [0] dactylus equal or shorter than half length of propodus; [1] dactylus longer than half propodus

33. Peraeopod 7, length of merus: [0] unexpanded; [1] lengthened to less than half carpus, or reaching half of carpus; [2] reaching more than half carpus

34. Pleonite 3 overlapping telson: [0] no; [1] covering telson partially or fully

Urosome with telson:

35. Urosomites: [0] free; [1] partly coalesced

36. Uropod 3, rami: [0] two; [1] less than two

37. Uropod 3 partly fused with telson: [0] no; [1] yes

38. Uropod 3, length ratio of (longer) ramus - peduncle: [0] ramus longer than peduncle; [1] ramus subequal or shorter than peduncle

39. Uropod 3, peduncle with marginal robust setae: [0] yes; [1] no
40. Telson, length: [0] shorter or equal $150 \%$ width; [1] longer than $150 \%$ width

41. Telson, robust setae: [0] present; [1] absent

42. Telson, shape: [0] horizontal, dorsoventrally flat $=$ depressed, thin and flappable; [1] vertically inflated, three-dimensional (see Fig. 10 proboliscid stenothoid); [2] with vertical area strongly enlarged, laterally flat $=$ compressed (see Fig. 3)

43. Telson, dorsal surface: [0] smooth; [1] forming a keel

\section{Results}

(Aa; Fig. 4) The first run (using matrix A, a heuristic, parsimonious analysis with all characters unordered) yielded a strict consensus tree of 269 best trees of 401 steps: the Amphilochids, Cressids and Cyproideids remained together as a clade near the Gammarus outgroup, and all thaumatelsonid genera kept together as a clade, with the root at the likewise Antarctic Paraprobolisca leptopoda and Probolisca ovata (both not well known, and possibly synonymous, see below), and with a single Arctic taxon, Pycnopyge carinatum near its base. The members of the genera Torometopa, Proboloides, Scaphodactylus, Stenothoe and Metopa are all scattered over the tree, and the situation for many genera thus remains unsolved.

When checking the character states for each character in this tree, it soon became clear, that many showed highly unlikely reversions, cases where complicated apomorphies had reverted to the plesiomorphic state.

(Ab; Fig. 5) Thus our next step led us to constrain certain characters: we left 29 characters unordered, defined changes in character states in 11 of the 43 as irreversible, had one character ordered and built a step matrix for two of the characters.

The following changes in 11 characters were defined as irreversible (all characters had the same weight of 1 and all were parsimony informative):

Chars. 1, 2. The special thickening of the peduncle of first antenna

Chars. 9, 10. Reduction and fusion of inner plate in the maxilliped

Char. 12. The loss of the second palp article in maxilla 1 
Char. 14. The broadening of coxa 4

Char. 21. The development of a distally free merus in gnathopod 1

Char. 26. Deep incisions in the palm of second gnathopod propodus

Char. 27. "Comb"-structures on the inner side of peraeopod dactyli

Char. 34. Pleonite 3 overlapping the telson

Char. 35. The fusion of urosomites

The size of the outer plates of the maxilliped in relation to merus length (Char. 11) was defined as ordered, while the state changes in the mandiblular palp (Char. 8) as well as the relative size of the merus tip in peraeopod 7 compared to the carpus length (Char. 33) were defined by a step matrix (see Table 2).

When running the analysis (Ab), with still 60 taxa in the in-group, and one (Gammarus) in the outgroup, we got a somewhat better resolved majority rule consensus tree, with 39 best trees of 439 steps (Fig. 5). The basis and the crown of the tree are quite similar to Aa (Fig. 4): the amphilochids form a clade with the out-group, although cressids and cyproideids now are found at base of the stenothoid tree. The thaumatelsonids once more form a well-defined clade with the basal genus Probolisca, but Pycnopyge now ends up in a clade together with other Arctic genera (Hardametopa, Mesometopa, Metopella, Vonimetopa, Zaikometopa), all characterized by a singlearticulated palp on maxilla 1 .

In clade 1, the basic clade within the family, we find the members of the genera Proboloides, Scaphodactylus and Torometopa, as well as the type species of the clearly very diverse genus Metopa (see also Fig. 4). There is also a large group in the middle (clade 2), containing the insufficiently described Paraprobolisca, all of the included species of Stenothoe, and some of the monotypic genera. The included species of Metopa are still scattered among

Table 2. List of constrained characters defined as step matrices. Abbreviations: $\mathrm{i}=$ irreversible.

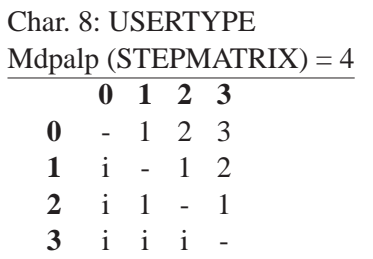

Char. 33: USERTYPE $\underline{\text { merustip (STEPMATRIX) }=3}$

$\begin{array}{llll}\mathbf{0} & - & 1 & 1 \\ \mathbf{1} & \mathrm{i} & - & 1 \\ \mathbf{2} & \mathrm{i} & \mathrm{i} & -\end{array}$

clades 1, 2 and 4, however, indicating once more that this large genus is probably not monophyletic.

Working on the advise of Brandt and Poore (2003: 903), who found that reweighting of previously unweighted characters brought them a considerable better solution of the resulting trees, we tested this also for our case: A procedure of unordered characters re-weighted after their Rescaled Consistency Index (RC) brought again the identical apomorphic clade of thaumatelsonids as well as all the nonstenothoids at the base of the tree; also clade 4 (in Fig. 5) emerged as a sister group of the thaumatelsonids. However, unlike in the unweighted run, the members of Stenothoe, Torometopa and Proboloides were distibuted among different clades. Re-weighting by the Consistency Index (CI) kept Torometopa and Proboloides together, but Stenothoe, Scaphodactylus as well as Metopa were paraphyletic. The re-weighted characters by the Retention Index yielded the lowest resolution in the middle of the tree, and the above mentioned genera emerged as paraphyletic taxa.

(Bc; Figs. 7, 8) As a next step, only the type species of each genus were included, and also the outgroup was diminished, to receive a number of taxa less than the number of characters (41 species, Gammarus sp. and Gitana sarsi in the out-group, and 43 characters). In addition to the changes in Ab, we defined the shape of peraeopod 7 as an irreversible character state, and for the number of articles in the palp of maxilla 1 , we changed the weight from 1 to 5. All other parameters were left unchanged from the constraint analysis before. The resulting 50\% Majority Rule consensus tree (see Fig. 7: 374 steps, 36 trees, CI 0,21, RI 0,49) confirmed again that the reduction from an expanded to a narrow basis on peraeopod 7 is present in more than one clade: in the Antarctic thaumatelsonid clade, with Probolisca as starting point, and in the Atlantic mesometopids, which are distinguished from the thaumatelsonids in mouthparts and structure of urosome. Fig. 8 shows the distribution of the states of character 31 (the additionally as irreversible defined basis-shape of peraeopod 7) within the 39 stenothoid genera.

(Bd; Fig. 9) Finally, we wanted to run our reduced matrix with alternative heuristic search options to test whether it was possible to obtain shorter most parsimonious trees (MPTs) or a higher number of 
Fig. 6. Matrix of 41 taxa and 45 characters.

Gammarus sp.

Gitana sarsi

Metopa clypeata

Metopoides magellanica

Proboloides gregaria

Parametopa crassicornis

Stenula rubrovittata

Parametopella cypris

Mesostenothoides perrieri

Metopelloides micropalpa

Aurometopa aurorae

Hardametopa nasuta

Knysmetopa grandimana

Mesometopa neglecta

Mesoproboloides excavata

Metopella longimana

Parametopa kervillei

Probolisca ovata

Prometopa tuberculata

Prostenothoe sextone

Scaphodactylus foliodactylus

Stenothoe valida

Torometopa crenatipalmata

Vonimetopa dubia

Wallametopa cabon

Zaikometopa erythrophthalmus

Antatelson walkeri

Ausatelson ule

Chucullba alla

Goratelson warroo

Parathaumatelson nasicum

Prothaumatelson nasutum

Pseudothaumatelson patagonicum 1

Pycnopyge carinatum

Ptychotelson virdurorum

Raumahara dertoo

Raukumara rongo

Thaumatelson herdmani

Thaumatelsonella kingelepha

Verticotelson mantis

Yarra unguiserra
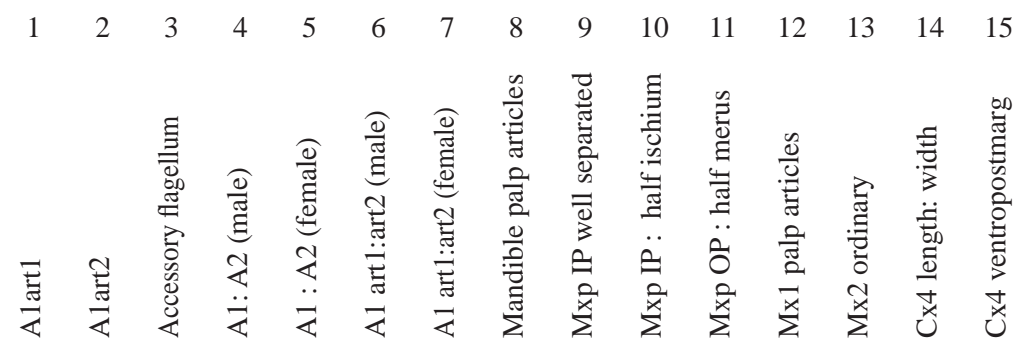

16

18

19

\begin{tabular}{|c|c|c|c|}
\hline 0 & 0 & 0 & 0 \\
\hline 0 & 0 & 1 & 0 \\
\hline 0 & 0 & 1 & 0 \\
\hline 0 & 0 & 0 & ? \\
\hline 0 & 0 & 1 & 1 \\
\hline 0 & 0 & 1 & 1 \\
\hline 0 & 0 & 1 & 1 \\
\hline 0 & 0 & 1 & ? \\
\hline 0 & 0 & 1 & 2 \\
\hline 0 & 0 & 1 & 1 \\
\hline 0 & 0 & 1 & 1 \\
\hline 1 & 0 & 1 & ? \\
\hline 0 & 0 & 1 & 0 \\
\hline 0 & 0 & 1 & ? \\
\hline 0 & 0 & 1 & 1 \\
\hline 0 & 0 & 1 & 1 \\
\hline 1 & 0 & 1 & 1 \\
\hline 0 & 0 & 0 & ? \\
\hline 1 & 0 & 0 & 2 \\
\hline 0 & 0 & 1 & 1 \\
\hline 0 & 0 & 0 & 0 \\
\hline 0 & 0 & 1 & 2 \\
\hline 0 & 0 & 1 & ? \\
\hline 0 & 0 & 1 & 2 \\
\hline 0 & 0 & 1 & 0 \\
\hline 1 & 0 & 1 & ? \\
\hline 1 & 0 & 0 & 1 \\
\hline 1 & 0 & 1 & 0 \\
\hline 1 & 0 & 1 & 0 \\
\hline 0 & 0 & 1 & 0 \\
\hline 1 & 0 & 1 & 0 \\
\hline 1 & 0 & 1 & 0 \\
\hline$n 1$ & 0 & 1 & 0 \\
\hline 0 & 0 & 0 & 1 \\
\hline 0 & 1 & 0 & 0 \\
\hline 0 & 1 & 1 & 0 \\
\hline 0 & 0 & 0 & 0 \\
\hline 0 & 1 & 1 & 0 \\
\hline 1 & 0 & 1 & 0 \\
\hline 1 & 0 & 0 & 2 \\
\hline 0 & 1 & 0 & 0 \\
\hline
\end{tabular}

$\begin{array}{ll}1 & 1 \\ 1 & 1 \\ 1 & 1 \\ ? & 0 \\ 0 & 1 \\ 0 & ? \\ 0 & 0 \\ ? & 0 \\ 0 & ? \\ 0 & 0 \\ 0 & ? \\ 0 & 0 \\ 0 & ? \\ 0 & 1 \\ 0 & 0 \\ 1 & 0 \\ 0 & 0 \\ ? & 0 \\ 0 & 0 \\ 0 & ? \\ 0 & 0 \\ 1 & 1 \\ ? & 2 \\ 0 & ? \\ 1 & ? \\ ? & 0 \\ 0 & 0 \\ 0 & 0 \\ 0 & 0 \\ 0 & 0 \\ 0 & 0 \\ 0 & 0 \\ 0 & 0 \\ 0 & 0 \\ 0 & 0 \\ 0 & 0 \\ 0 & 0 \\ 0 & 0 \\ 0 & 0 \\ 0 & 0 \\ 0 & 0 \\ & \\ & \\ & \end{array}$

MPTs. For this run, we left all characters unordered and unweighted and changed the heuristic search options as follows: addition sequence $=$ random, with 10 replicates (see detailed description in Material and Methods). The Majority Rule consensus tree (Fig. 9) shows a well-defined clade with thaumatelsonids, another with mesometopids, but proboloidids and stenothoids are mingled. This was to be expected, as here are several large, very diverse, and probably not monophyletic genera, and only the type species are prepresented in this study.

\section{Discussion and conclusions}

\section{Clades within Stenothoidae}

As mentioned above, this investigation is to be considered a preliminary study, which needs to be followed up by studies of smaller groupings within this large family. On the basis of the present analyses we recognize the following groups (see mainly Fig. 5), which for the time being will not be named formally: 


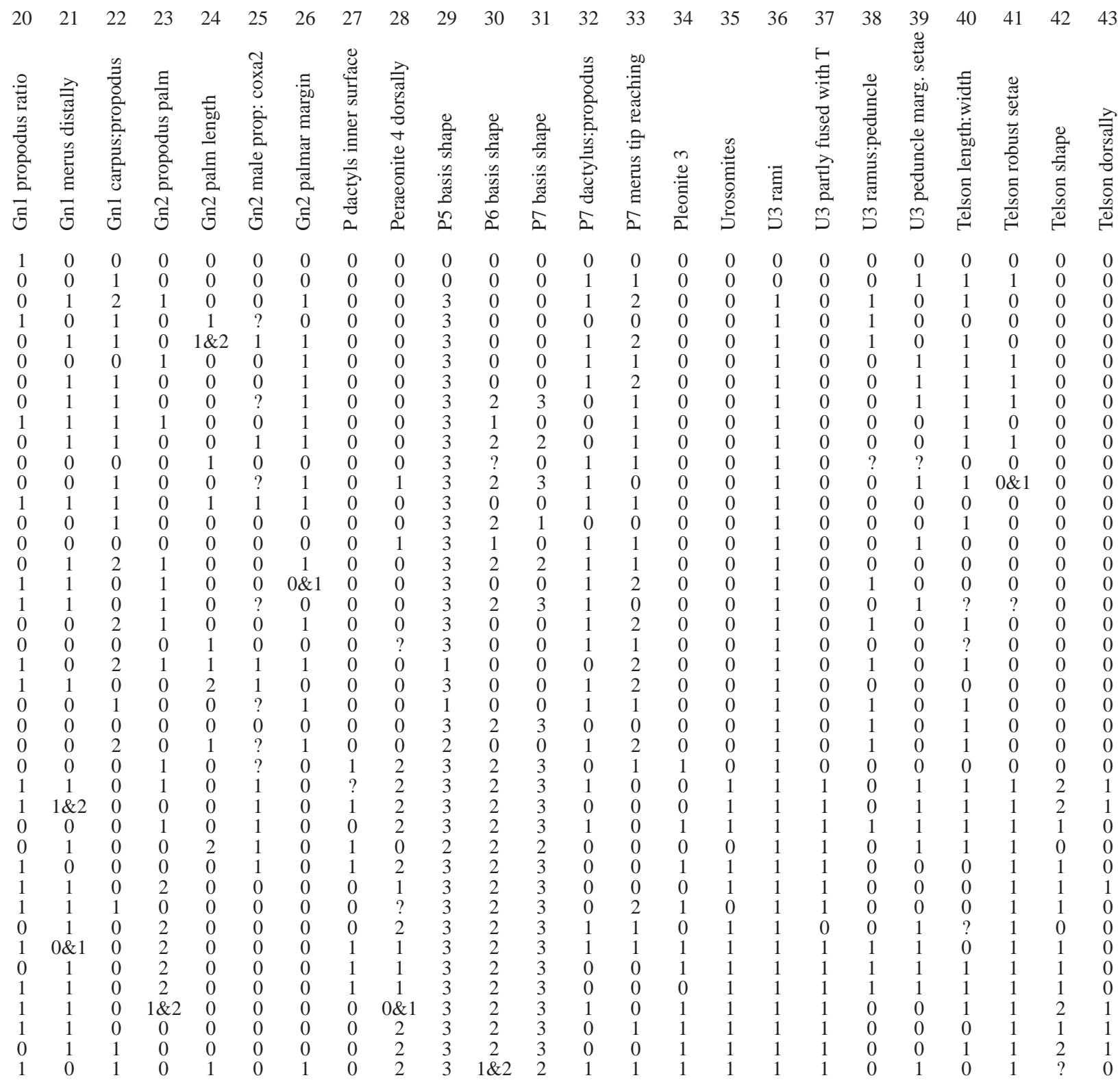

Clade 1. This group is composed mainly of Proboloides, Torometopa and Scaphodactylus, as well as the type species of Metopa , M. clypeata. Important common characters of this clade are: a clear sexual dimorphism (propodi of gnathopod 1, 2 are different in shape, and considerably in size); gnathopod 1 is often simple and the merus longer than the propodus; gnathopod 2 has the propodus in many cases deeply serrated and/or incised; peraeopod 7 has the merus distally lengthened and widened, and in uropod 3 the ramus is shorter than the peduncle. In females pe- duncular articles 1 and 2 of antenna 1 are subequal, while in males article 1 is longer than article 2. Coxa 4 is about as long as wide and not conspicuously enlarged.

This group is quite cohesive, apart from the case of Metopa. The type species of the genus Metopa is poorly described, may not belong here, and is not very representative for the majority of the extant species of Metopa. Other - still quite diverse - species of Metopa , chosen to evaluate the monophyly of this genus and included in the first analysis, do not emerge 


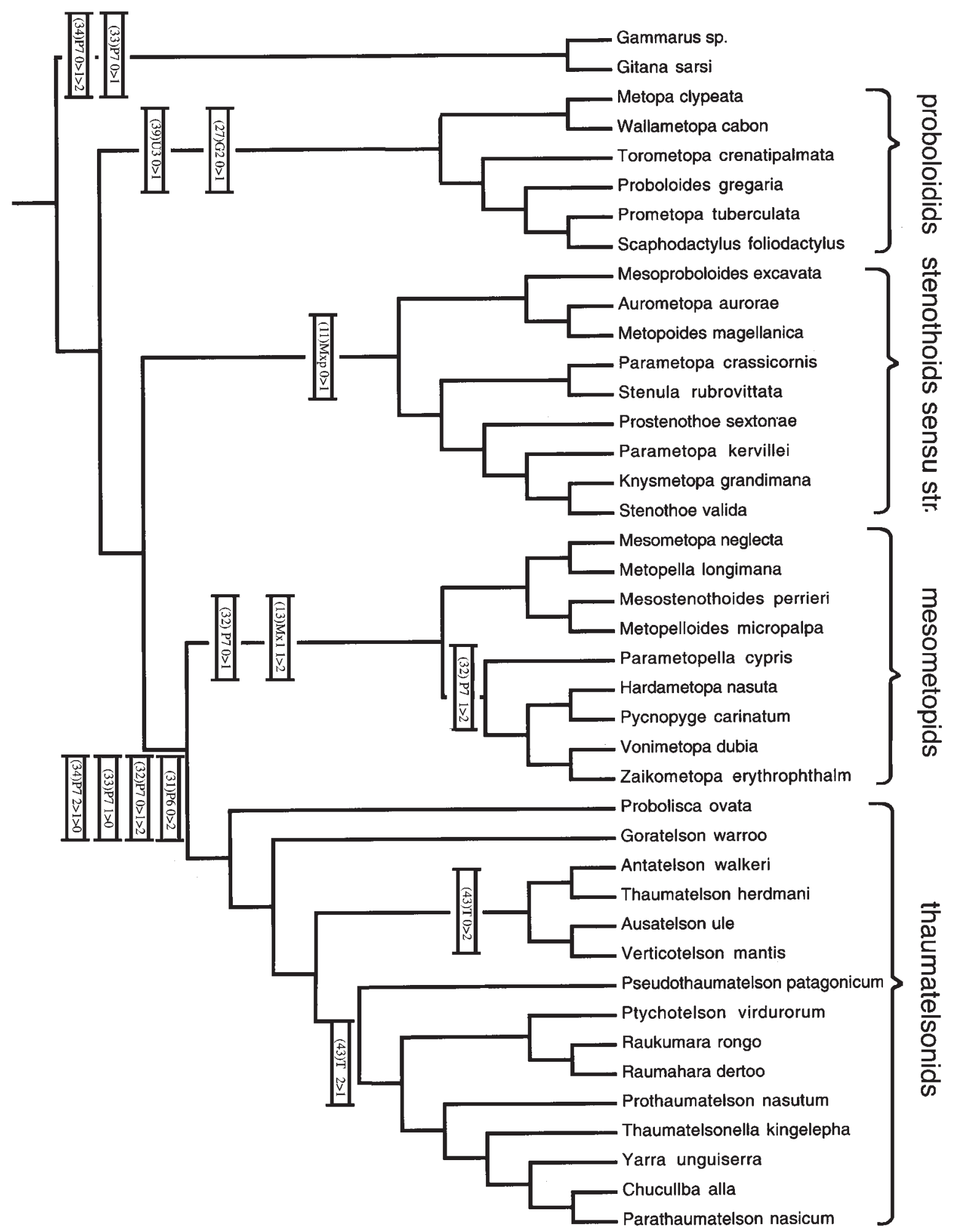

Fig. 7: Constrained analysis of 41 species and 43 characters: 12 irreversible characters (Mx1 palp articles having weight 5, all others weight 1), one ordered and two user-defined: 50\% Majority Rule consensus tree of 36 trees; length = 374; CI = 0,21, RI = 0,49. 


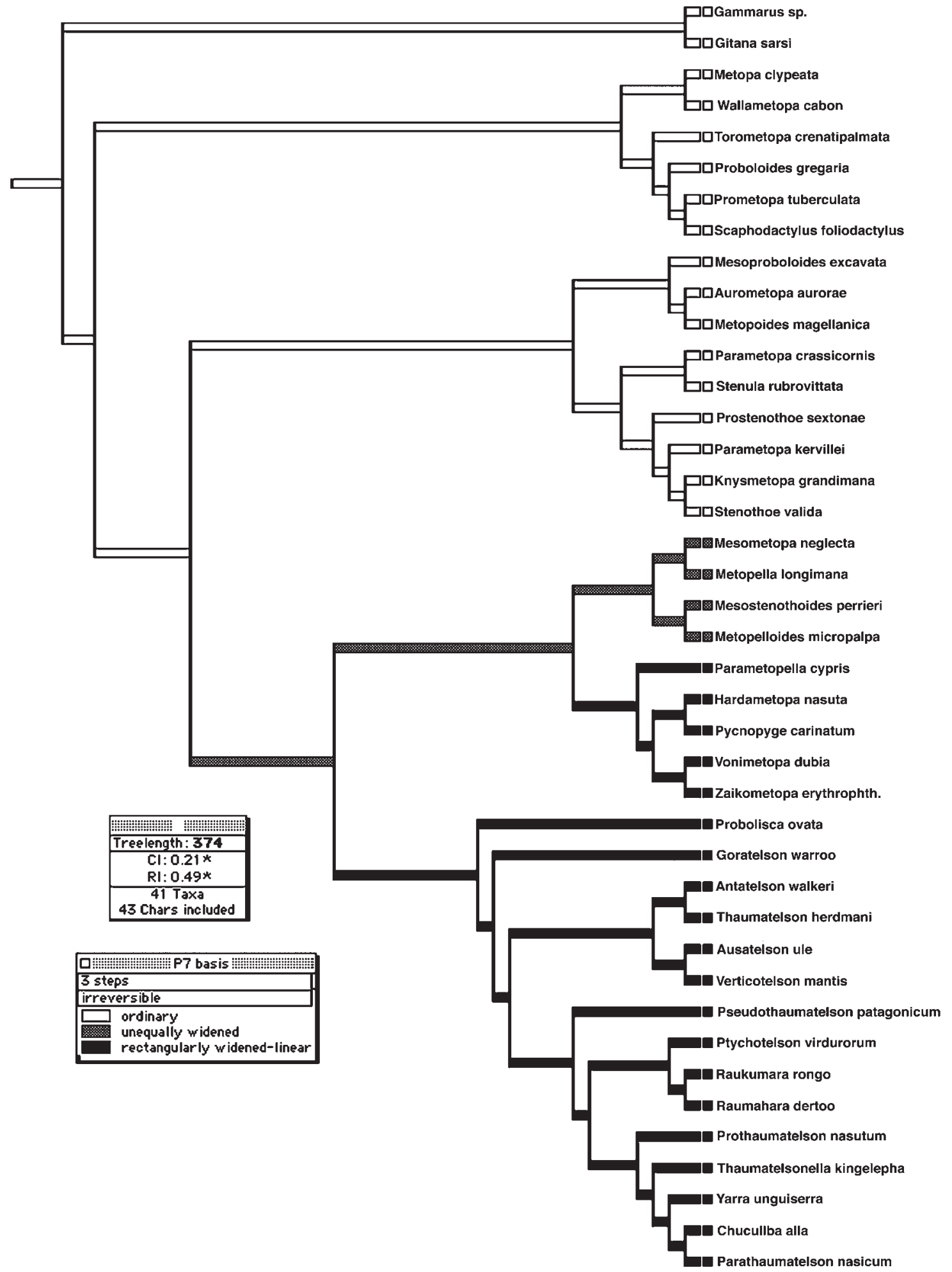

Fig. 8: Distribution of character 31 (basis of peraeopod 7) within the stenothoid genera, after defining it as irreversible. 


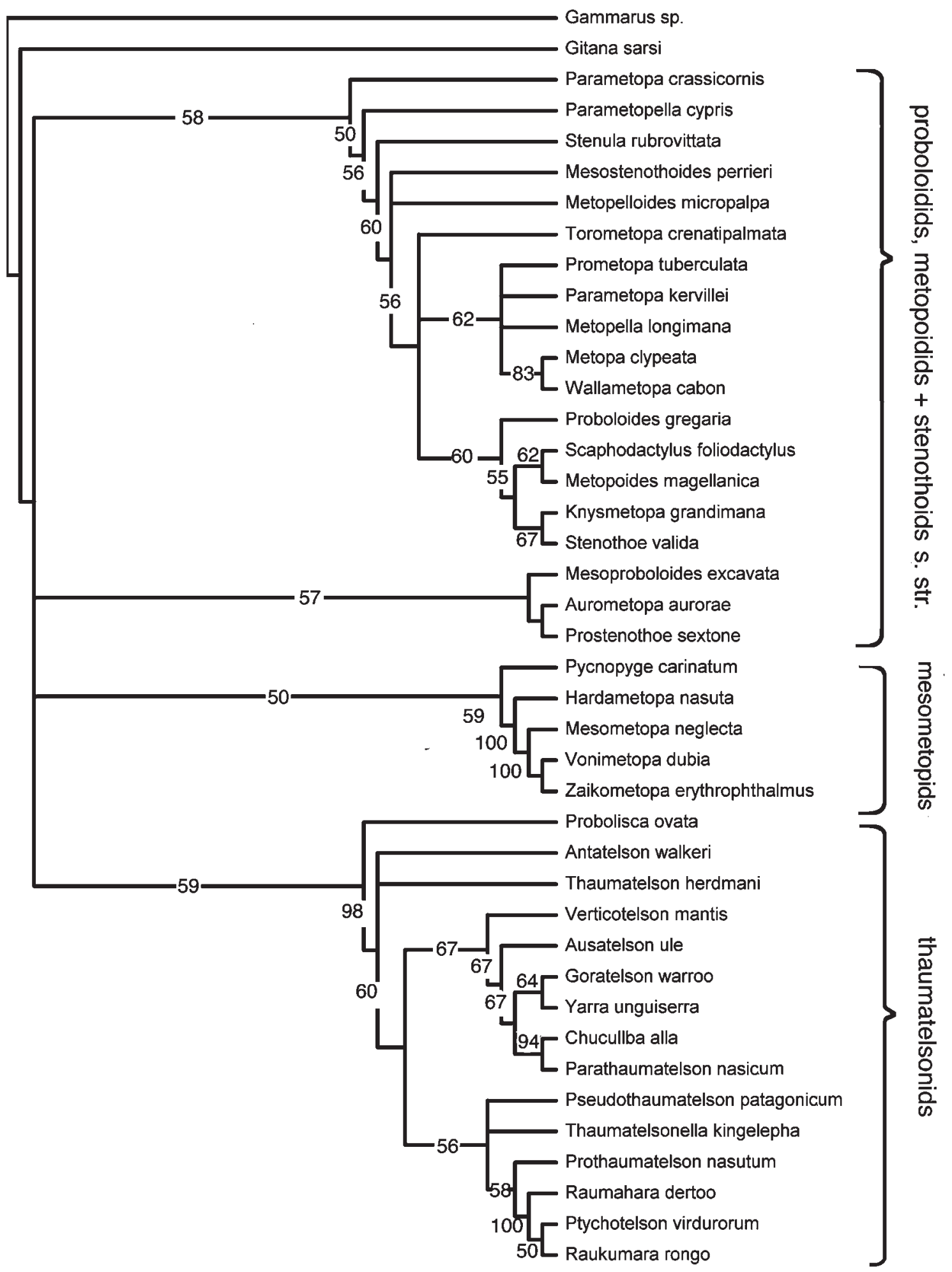

Fig. 9: Unconstrained analysis of 41 taxa, 43 characters, using addition sequence = random (20 replicates); Majority Rule consensus of 2393 trees, length $=357$ steps $($ min. steps $=56 ;$ max. steps $=624) ; \mathrm{CI}=0.157, \mathrm{RI}=0.470 ; \mathrm{RC}=0.074 ; \mathrm{HI}=0.843$. 
in clade 1 . The genera at the root of this clade, Torometopa and Scaphodactylus, are characterized by the presence of smaller or larger expanded lobes posterodistally on an otherwise narrow basis of peraeopod 5, while all other genera in this group have a totally narrow rectolinear peraeopod 5 basis. For the time being we have informally named this group „proboloidid stenothoids“, after the first described genus, Proboloides. A detailed revision of this group is already in preparation.

Clade 2. This large clade seems as yet much less clearly resolved than the clades at the basis and crown of the cladogram. This may partly be because it contains the large, very diverse and not monophyletic genera Metopa and Stenothoe. The clade can be called the „stenothoids sensu stricto“; it can again be divided in three subclades, 2a, 2b and 2c.

The little known Paraprobolisca leptopoda Ren (in Ren and Huang, 1991) emerges at the basis of this group. This monotypic genus is extremely similar to Probolisca ovata (Stebbing, 1888): shape and size of the gnathopods are identical, most mouthparts match perfectly and both authors report a long but not normally articulated mandibular palp. While Stebbing (op. cit.: 65) „was unable to make out a division“ between a long second and a suspected third article, Thurston (1974: 26-27) reported that he found three very distinct articles, as had Schellenberg (1931: 314) before him. Stebbing's figure (op. cit.) is strikingly similar to Paraprobolisca by Ren, and shows only one long article in the mandibular palp; Ren (op. cit.) reports this long single article in his generic diagnosis as a differenciating character of his genus Paraprobolisca, but is convinced that there is also a very short basal article. The genus Probolisca contains at present 3 species, of which only P. ovata is (partly) reported with clearly 3 articles in the mandibular palp, the other species have one short and one long article in the mandibular palp.

Also Proboloides typicus is originally described as having a 2-articulate mandibular palp (Walker 1906: 14, 1907: 20 tav. 6 fig. 10); since this diagnosis is in agreement with that of Barnard and Karaman, we adopted this character state in our matrix. However, Schellenberg (1926 fig. 41) reported three very distinct articles. Probably the articulation between second and third article is sometimes more or less clearly visible and therefore the character state „mandible palp with 2 articles“ should better be avoided.

The second character diagnosing Paraprobolisca according to Ren (op. cit.) is a ramus on uropod 3 which Ren calls one-articulate. Ren's illustration is otherwise completely similar to that of Probolisca ovata, but the articulation between the two articles of the uropod 3 ramus is lacking. It is highly probable that this articulation has simply been overlooked, and that Paraprobolisca leptopoda is a junior synonym of Probolisca ovata, but a re-examination of type material as well as ample additional material seems necessary. In these analyses, Paraprobolisca has been with the exact character states as given by Ren, and therefore it comes out differently from Probolisca.

Clade 2a in the cladogram (in Fig. 5) suggests a comparison between Stenothoe ascidiae, originally described as Microstenothoe by Pirlot, 1933 and Prostenothoe sextonae Gurjanova, 1936, joined in the same small clade. Body-shape and size are similar in the two species, but one was found on ascidians along the French Atlantic coast, the other in the Japan Sea. Microstenothoe ascidiae lacks a mandibular palp (at least it was not found), thus was merged with Stenothoe, while Prostenothoe is described as having a very tiny 1-articulate palp. These two species seem closely related and should definitely belong to the same genus. But this assignment will probably have to await a revision of the Stenothoe - complex.

The following clade $2 b$ (Fig. 5) contains mainly some of the most diverse members of Stenothoe (with S. valida as genero-type), clustering around Montaguana monoculoides, now generally considered a senior synonym of Stenothoe. In addition, the morphologically aberrant genera Knysmetopa and Parametopa come out here, probably because they too lack a mandibular palp. As shown above for Probolisca and Proboloides, this character seems to vary even between closely related species, and it has probably received too much weight hitherto in the classification of the Stenothoidae.

In clade 2c of Fig. 5, species are found with one or no article in the accessory flagellum, 1-articulate palp on maxilla 1, and one or no articles on the mandibular palp: Stenula carinata as well as Metopa leptocarpa have the first gnathopod rectipalmate, otherwise they seem clearly two different species, although in $M$. leptocarpa no details about the mouthparts are known. The other taxa in this clade show a ,transition gradient" concerning the posterior peraeopods. As mentioned earlier (Krapp-Schickel, 1996: 113) in the Amphilochidae, the basis of peraeopods 5-7 is always expanded and rounded (eurypody), while peraeopod 

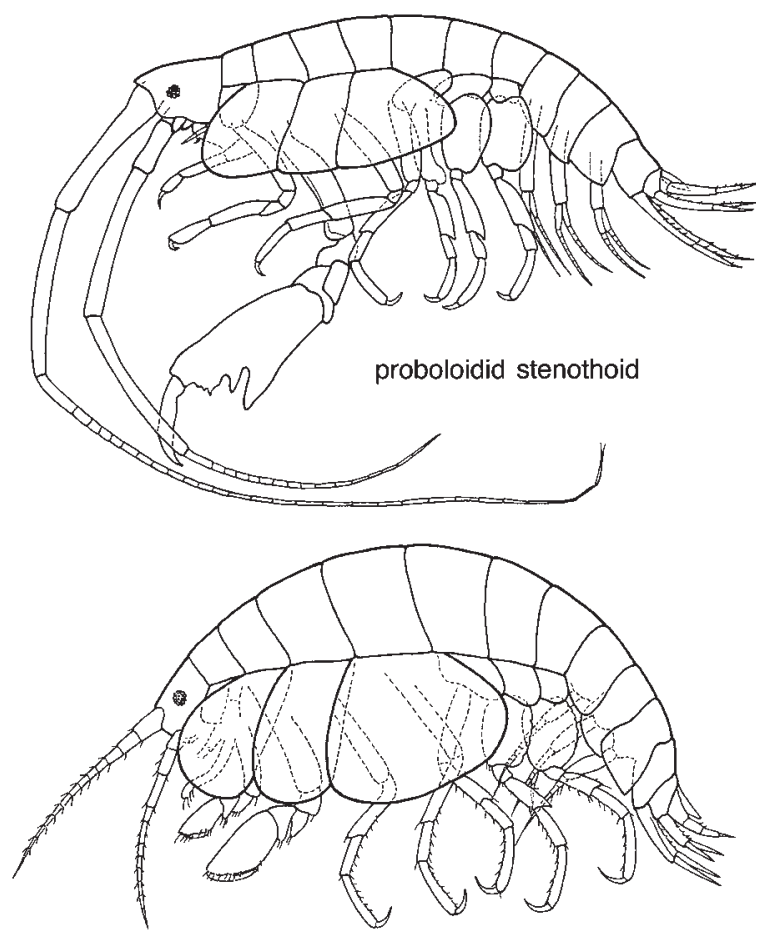

stenothoid sensu stricto

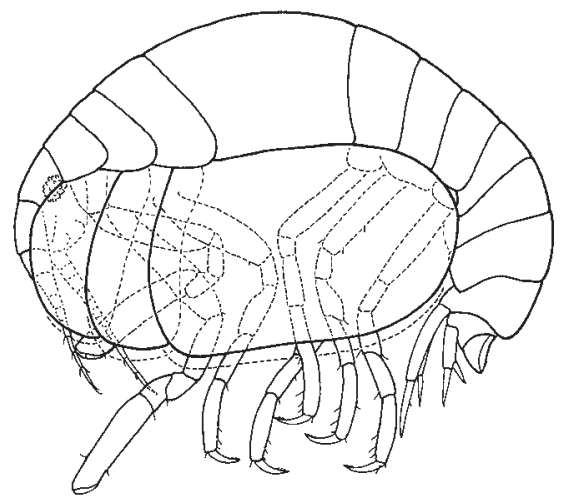

thaumatelsonid

Fig. 10: Habitus of a proboloidid stenothoid (Scaphodactylus gigantocheirus Rauschert and Andres), a stenothoid sensu stricto (Stenothoe tergestina (Nebeski) and a thaumatelsonid (Chucullba warea Barnard).

5 is slim and slender in all Stenothoidae (stenopody), and there is a tendency to reduce also peraeopod 6 and 7. Undoubtedly, there is an interaction between the increasing widening of coxa 4 and the narrowing of the basis of peraeopod 6 and 7 .

Metopella, Metopelloides and Mesostenothoides are in our tree separated, but in the later analyses with a more restricted matrix (Fig. 7), all end up in the same clade. All these genera have a transitional position, concerning the shape of peraeopodal bases: Metopelloides micropalpa has a distally widened, bottle-shaped basis of peraeopod 7 and slender peraeopods 5 and 6; in Metopella, the species angusta has a slim basis on peraeopods 5 to 7 ; M. longimana has peaeopod 5 and 6 slim, but the basis of peraeopod 7 rectangularly broadened.

Clade 3 contains a small group of genera with a tiny accessory flagellum and a mandibular palp with a very short third article: Mesoproboloides (with few species), Aurometopa (monotypic) and Metopoides. While Metopoides has a regularly rounded basis on peraeopod 6, in Mesoproboloides excavata (the genero-type) it is rectangularly narrowed, in Aurometopa it is described as being different from peraeopod 7 (but not shown in figures). However, this sole character seems insufficient to erect separate genera, as several other genera contain species with transitions. Aurometopa aurorae (Nicholls, 1938, cf. Barnard and Karaman, 1987) is otherwise very similar to Metopoides sarsii (Pfeffer, 1888), which also has peraeopod 6 with a broad rectangular shape. Both species have an Antarctic distribution, and the two taxa, although valid species, probably belong to the same genus; however, both need a thorough redescription. This clade could be called the „metopoidid clade“. In the constraint tree (Fig. 7) these show up together with the „stenothoids sensu stricto“, thus in our summary they are not considered as one of the major resulting groups.

Clade 4. Here are taxa with 1 article on the palp of maxilla 1; all members have an Arctic distribution. Many of them have their anterior body end thickened and reinforced, and some also the posterior body end, but this probably evolved differently than in the Austral-Antarctic thaumatelsonids. Within this group, gnathopod 1 is often simple, and the reduction of the mandibular palp appears to have occurred more than once. Provisionally, this clade is named „mesometopid stenothoids“, again after the first described genus of the group. The other members are Hardametopa, Pycnopyge, Vonimetopa and Zaikometopa .

Clade 5. Here we find the „thaumatelsonid stenothoids“, first recognized as an independent family by Gurjanova (1938). Barnard (1964: 71, 1972a: 318, 1972b: 158-160) repeatedly studied and discussed this group. While starting with the idea of a separate family, he finally changed his mind and considered them as ,a polyphyletic group of highly specialized 
stenothoids in which modifications towards a solidified urosome have occurred in diverse ways“. After a detailed study of many insufficiently described and often tiny representatives, Krapp-Schickel (2000, 2006a) tested and confirmed its monophyly. In our present trees (Fig. 5, 7) this group turns out as sister clade of the mesometopids, and the genera Probolisca and Goratelson emerge at the basis of thaumatelsonids. The latter genus is highly aberrant, and although it has many treats linking it to the present group, it may in fact not be very closely related. Probolisca has been discussed earlier (see clade 2); the genus is insufficiently well described, and especially its mouthparts need thorough redescription (as already noted by Barnard and Karaman, 1991: 695). What was surmised already (Krapp-Schickel, 2000 and 2006a) is now tested: the Thaumatelsonidae form a monophyletic group.

Cladistic analysis is a powerful tool, but it has its limitations. Myers and Lowry (2003: 475) observed: "We are of the opinion that because the morphological data available from extant taxa alone are limited, and because taxonomists are able to make use of only a minute proportion of the potential phylogenetic information in the genome, statistical analyses of consensus trees are inappropriate. Statistical techniques assume a level of precision in the data set, which is illusory. No tree is the correct representation of evolution. At a fundamental level, a tree is only as good as its character-state interpretation." Working as we did with $2 \mathrm{~mm}$ long animals, often described on the basis of one or two specimens, whose mouthparts are difficult to dissect and therefore often have not been described at all, and which are then placed as often as not into monotypic genera, it is clear that we lack in many cases the proper tools for a correct character-state interpretation.

Traditionally the Stenothoidae have been divided into genera on the basis of

a mouthpart reduction,

b reduction of the originally broadened bases of the posterior peraeopods or

c special developments (,reinforcements“) in the antennae and the urosome.

It has become clear to us that only a combination of all these different characters may shed more light on the evolutionary history of the family. In this we are further hampered by our ignorance, in very many cases, of the lifestyle of the various species, and of the correlations between lifestyle and morphology. We know that some species (good swimmers with moderately enlarged coxa 4 , a broadened basis on peraeopod 6 and a more or less well developed sexual dimorphism) live as commensals. Other species live interstitially; these have often an "ostracod habitus", with weak and thin legs hidden under a huge rectangular shield-like coxa 4; they show no sexual dimorphism and can at best crawl, but not swim well. But for many taxa we do not know anything about their lifestyle.

We can, however, deduce some ideas and hypotheses from the analyses presented here: Mouthpart reduction does at best seem to play a role in the fine tuning of stenothoid systematics, while the overall character evolution within the family appears to have gone from fully rounded bases on peraeopod 6 and 7 and a not very large coxa 4, to a much larger coxa 4, combined with tender and slim bases on posterior peraeopods (in advanced types often combined with specializations in antennae and urosome). The first type of animals is found in the proboloidid clade, and the most advanced ones in the probably independently developed clades 4 and 5, the mesometopid stenothoids and the thaumatelsonids, which have probably evolved independently.

For the time being, and for practical purposes, we recognize the following five informally named clades: the proboloidid stenothoids at the base, the stenothoids, now sensu stricto, as an as yet not well resolved group in the centre, the small unit of metopoidid stenothoids (in some analyses merged in the stenothoid clade), the mesometopid stenothoids, and the thaumatelsonids as most advanced group, which shows as synapomorphies not only the reduction of the basis of peraeopod 6, 7, but also a series of very specialized changes and "reinforcements" of the urosome + telson, as well as thickened antennal peduncles. For general characters see Fig. 10. Future research, including thorough redescriptions of as many nominal taxa as possible, will address these clades one at a time, and will i.a. without much doubt result in a total restructuring of the large, unwieldy and now very diverse genera Metopa and Stenothoe.

Future research will also have to show whether it will be necessary to divide the family Stenothoidae into several families. At the moment it seems well enough established, however, that the thaumatelsonids are a monophyletic and independent clade, dif- 
fering from the rest of the stenothoids in many synapomorphies (see above, and similarly to the cyproideids formerly being within Amphilochidae).

Diagnosis: Antenna 1 peduncle article 1 or 2 with nasiform process; accessory flagellum $0-2$ articulate. Mouthparts: mandibular palp 0-3 articles; maxilla 1 inner plate feeble, palp with 2 articles; maxilla 2 small, stout, poorly setose, inner plate much smaller than outer, next to or even riding on the outer one. Peraeopods 5-7 weak, basis narrow, slim, mostly hidden by the rectangularly broadened coxa 4. Uropod 3 with one usually 2-articulate ramus. Urosomites partially fused, sometimes protected by overlapping pleosomite 3. Telson three-dimensionally thickened, boat-shaped or vertically elevated.

15 included genera in alphabetic order:

Antatelson Barnard
Ausatelson Barnard
Chucullba Barnard
Goratelson Barnard
Parathaumatelson Gurjanova
Probolisca Gurjanova
Prothaumatelson Schellenberg
Pseudothaumatelson Schellenberg
Ptychotelson Krapp-Schickel
Raumahara Barnard
Raukumara Krapp-Schickel
Thaumatelson Walker
Thaumatelsonella Rauschert and Andres
Verticotelson Krapp-Schickel
Yarra Krapp-Schickel

As the remaining stenothoid clades would become paraphyletic after the removal of the thaumatelsonids, we have to wait with reinstating until all clades will be defined as formal nominal taxa.

\section{Acknowledgements}

We like to thank Sandro Ruffo, Jim Lowry, Hans Georg Andres, Wim Vader, Jørgen Berge, and Gary Poore for their advise, reviews and help in many stages, sometimes over decades, of this work on the stenothoid amphipods.

\section{References}

Barnard JL. 1964. Revision of some families, genera and species of gammaridean Amphipoda. Crustaceana 7: 49-74, 2 tab.

Barnard JL. 1972a. Gammaridean Amphipod of Australia, Part I. Smithson. Contrib. Zool. 103: 1-333.

Barnard JL. 1972b. The marine fauna of New Zealand: algaeliving littoral Gammaridea (Crustacea Amphipoda). Mem. New Zealand Oceanogr. Inst. 62: 7-216.

Barnard JL, Karaman G. 1987. Revisions in classification of gammaridean Amphipoda (Crustacea) part 3. Proc. Biol. Soc. Washington 100: 856-875.

Barnard JL, Karaman G. 1991. The Families and Genera of Marine Gammaridean Amphipoda (Except Marine Gammaroids), Part 1,2. Rec. Austral. Mus., Suppl. 13: 1-866.

Brandt A, Poore G. 2003. Higher classification of flabelliferan and related Isopoda based on a reappraisal of relationships. Invert. Syst. 17: 893-923.

Gurjanova E. 1938. Amphipoda, Gammaroidea of Siaukhu Bay and Sudzukhe Bay (Japan Sea). Rep. Japan Sea Hydrobiol. Exped. Zool. Inst. Acad. Sci. USSR in 1934 1: 241-404.

Krapp-Schickel T. 1996. New data on Stenothoids (Crustacea, Amphipoda). Mitt. Hamb. Zool. Mus. Inst. 93: 93-120.

Krapp-Schickel T. 2000. Thaumatelsonine stenothoids (Crustacea: Amphipoda): Part 1. Mem. Mus. Victoria 58/1: 89-124.

Krapp-Schickel T. 2006a. Thaumatelsonine Stenothoids (Crustacea: Amphipoda) Part 2. Zootaxa 1165: 1-31.

Maddison DR, Maddison WP. 2003. MacClade 4.06. Sinauer Assoc., Sunderland, Massachusetts.

Myers AA, Lowry JL. 2003. A phylogeny and a new classification of the Corophiidea Leach, 1814 (Amphipoda). J. Crust. Biol. 23/2: 443-485.

Pfeffer G. 1888. Die Krebse von Südgeorgien nach der Ausbeute der Deutschen Station 1882-83. 2. Teil. Die Amphipoden. Jahrbuch der Wissenschaftlichen Anstalten zu Hamburg 5: 76-142.

Ren X, Huang L. 1991. Studies on Gammaridea and Caprellidea (Crustacea: Amphipoda) from the northwest waters off Antarctic Peninsula. Stud. mar. Sin. 32: 187-323 (Chinese; translation of description of the new species in English).

Schellenberg A. 1931. Gammariden und Caprelliden des Magellangebietes, Südgeorgiens und der Westantarktis. Further Zool. Res. Swed. Antarct. Exped. 1901-03: 2/6: 1-290.

Swofford DL. 2002. PAUP version 4.0b81. Sinauer Ass., Sunderland, Massachusetts.

Stebbing TRR. 1888. Report on the Amphipoda collected by H.M.S. Challenger during the years 1873-76. 29: Zoology. London: Eyre and Spottiswoodie: XXIV + 1737 pp., 210 pls.

Thurston HM. 1974. The Crustacea Amphipoda of Signy Island, south Orkney Islands. Brit. Antarct. Surv., Sci. Rep. 71: 1-133.

Received: 24 April 2006

Accepted: 8 September 2006 